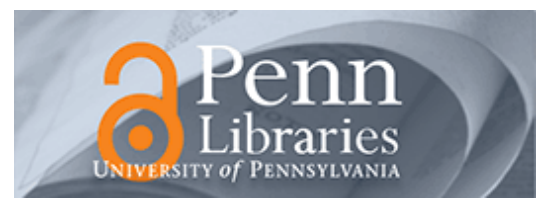

University of Pennsylvania

ScholarlyCommons

Health Care Management Papers

Wharton Faculty Research

8-2007

\title{
Aching to Retire? The Rise in the Full Retirement age and its Impact on the Social Security Disability Rolls
}

Mark Duggan

University of Pennsylvania

Perry Singleton

Jae Song

Follow this and additional works at: https://repository.upenn.edu/hcmg_papers

Part of the Other Economics Commons, Other Education Commons, and the Public Economics Commons

\section{Recommended Citation}

Duggan, M., Singleton, P., \& Song, J. (2007). Aching to Retire? The Rise in the Full Retirement age and its Impact on the Social Security Disability Rolls. Journal of Public Economics, 91 (7-8), 1327-1350.

http://dx.doi.org/10.1016/j.jpubeco.2006.12.007

This paper is posted at ScholarlyCommons. https://repository.upenn.edu/hcmg_papers/107

For more information, please contact repository@pobox.upenn.edu. 


\title{
Aching to Retire? The Rise in the Full Retirement age and its Impact on the Social Security Disability Rolls
}

\begin{abstract}
The Social Security Amendments of 1983 reduced the generosity of Social Security retired worker benefits in the U.S. by increasing the program's full retirement age from 65 to 67 and increasing the penalty for claiming benefits at the early retirement age of 62 . These changes were phased in gradually, so that individuals born in or before 1937 were unaffected and those born in 1960 or later were fully affected. No corresponding changes were made to the program's disabled worker benefits, and thus the relative generosity of Social Security Disability Insurance (SSDI) benefits increased. In this paper, we investigate the effect of the Amendments on SSDI enrollment by exploiting variation across birth cohorts in the policy-induced reduction in the present value of retired worker benefits. Our findings indicate that the Amendments significantly increased SSDI enrollment since 1983 , with an additional $0.6 \%$ of men and $0.9 \%$ of women between the ages of 45 and 64 receiving SSDI benefits in 2005 as a result of the changes. Our results further indicate that these effects will continue to increase during the next two decades, as those fully exposed to the reduction in retirement benefit generosity reach their fifties and early sixties.
\end{abstract}

\section{Keywords}

disability, retirement, social security

\section{Disciplines}

Other Economics | Other Education | Public Economics 


\title{
Aching to Retire? The Rise in the Full Retirement Age and its Impact on the Social Security Disability Rolls
}

\author{
January 2007 \\ Mark Duggan \\ University of Maryland, \\ Brookings Institution, and NBER \\ duggan@econ.umd.edu \\ Perry Singleton \\ University of Maryland \\ singleto@econ.bsos.umd.edu \\ Jae Song \\ Social Security Administration \\ Jae.Song@ssa.gov
}

The authors are especially grateful to Emmanuel Saez and two anonymous referees for comments that substantially improved this paper. We are also indebted to David Autor, Moshe Buchinsky, Ed DeMarco, Bill Evans, Jonah Gelbach, Patrick Healy, Judy Hellerstein, John Hennessy, Howard Iams, Jeff Kling, Erzo Luttmer, Joyce Manchester, L. Scott Muller, John Rust, Seth Sanders, Michael Wiseman, and to numerous seminar participants for helpful suggestions. Thanks also to the many employees of the Social Security Administration who assisted us with the data used in this paper. Duggan thanks the Alfred P. Sloan Foundation for support. The corresponding author (Duggan) can be contacted at: University of Maryland, Department or at the email address above. The conclusions and opinions expressed in this paper are solely those of the authors and should not be construed as representing the opinions or policies of the Social Security Administration or any agency of the Federal Government. All errors are our own. 


\begin{abstract}
$\underline{\text { Abstract }}$
The Social Security Amendments of 1983 reduced the generosity of Social Security retired worker benefits in the U.S. by increasing the program's full retirement age from 65 to 67 and increasing the penalty for claiming benefits at the early retirement age of 62. These changes were phased in gradually, so that individuals born in or before 1937 were unaffected and those born in 1960 or later were fully affected. No corresponding changes were made to the program's disabled worker benefits, and thus the relative generosity of Social Security Disability Insurance (SSDI) benefits increased. In this paper, we investigate the effect of the Amendments on SSDI enrollment by exploiting variation across birth cohorts in the policy-induced reduction in the present value of retired worker benefits. Our findings indicate that the Amendments significantly increased SSDI enrollment since 1983, with an additional 0.6 percent of men and 0.9 percent of women between the ages of 45 and 64 receiving SSDI benefits in 2005 as a result of the changes. Our results further indicate that these effects will continue to increase during the next two decades, as those fully exposed to the reduction in retirement benefit generosity reach their fifties and early sixties.
\end{abstract}




\section{Introduction}

During the last two decades, the fraction of adults in the U.S. receiving benefits from the Social Security Disability Insurance (SSDI) program has steadily increased. For example, among individuals between the ages of 45 and 64, the rate of SSDI enrollment rose from 4.5 percent in 1983 to 6.7 percent by 2005. A similarly striking increase occurred for younger workers, with the fraction of 25 to 44-year old workers on SSDI rising from 0.7 to 1.6 percent during this same period. A number of explanations have been advanced for the growth in SSDI enrollment, including a 1984 policy change that liberalized the program's medical eligibility criteria, the aging of the "baby boom" population, and an increase in female labor force attachment that resulted in more women being insured for SSDI (Autor and Duggan, 2006).

In this paper, we investigate whether and to what extent a policy-induced reduction in the generosity of Social Security retired worker benefits also contributed to the increase in SSDI enrollment. The Social Security Amendments of 1983, which were signed into law on April $20^{\text {th }}$ of that year, increased the age at which individuals were eligible for their full retirement benefits from 65 to 67 while simultaneously increasing the penalty for claiming benefits at the early retirement age of 62. Combined with an increase in the payroll tax rate and several other provisions, ${ }^{1}$ the main goal of this legislation was to improve the short and long-term fiscal health of Social Security, also known as the Old Age, Survivors, and Disability Insurance (OASDI) program.

As Figure 1 demonstrates, the increase in the full retirement age and in the early retirement penalty were phased in gradually and occurred in two main stages. Individuals born in 1937 or earlier were unaffected by the change, their counterparts born between 1938 and 1959 were partially affected, and those born in 1960 or later were fully affected. The first half of the policy change was phased in from the 1938 to 1943 birth cohorts while the second was phased in from the 1955 to 1960 birth cohorts. In each year of the phase-in, the full retirement age was increased in two-month

\footnotetext{
${ }^{1}$ For a full description of the 1983 Social Security Amendments, see http://www.ssa.gov/history/1983amend.html.
} 
increments and the fraction of full benefits that individuals could receive at the early retirement age of 62 fell by 0.833 percentage points. This latter change implied that the penalty for claiming at 62 increased from 20 to 30 percent of full benefits.

While the generosity of retired worker benefits declined as a result of the Amendments, no corresponding changes were made to SSDI benefits. Theoretically, it is plausible that some individuals who would have otherwise claimed retired worker benefits responded to this change by applying for and perhaps ultimately receiving SSDI benefits. All else equal, one would expect the incentive to do this to be significantly greater for those born in more recent years and for those closer to the age of claiming retired worker benefits. This is because year-of-birth and age are the key determinants of the decline in the value of retired worker benefits induced by the policy. ${ }^{2}$ As Figure 2 demonstrates, the decline at each age was three times larger for those born in 1943 than for their counterparts born in 1939. Similarly, the decline was almost twice as large in dollar terms for 62year olds as it was for 45 -year olds (\$8900 versus $\$ 4700$ for a man born in 1943).

To estimate the effect of the policy on SSDI enrollment, we exploit variation by cohort ${ }^{3}$ and by age in the change in the present value of retired worker benefits. More specifically, we estimate first difference models that control for age-specific trends in SSDI enrollment and for common changes in each year in SSDI enrollment. Our key explanatory variable is the change in the present value of retired worker benefits from one year to the next at a certain age. We focus primarily on estimating the effect of the first half of the policy described above, which was phased in from the 1938 to the 1943 birth cohorts, as those affected by the second half were relatively young and thus less likely to be affected in our most recent year of data.

We utilize aggregate data on SSDI enrollment rates by age, gender, and year-of-birth in each

\footnotetext{
${ }^{2}$ It is worth noting that the present value of retired worker benefits for the average individual has been steadily increasing over time, both because of the increase in life expectancy and because of the indexation of social security benefits to average wages. But we only consider the change in the present value that is caused by the policy, essentially assuming that these other changes are relatively smooth over time.

${ }^{3}$ Here and elsewhere in the paper we use the term cohort to refer to a specific year-of-birth.
} 
year from 1983 to 2005 and restrict attention to individuals between the ages of 45 and 64 . We essentially test whether SSDI enrollment increases more rapidly at each age when the present value of retired worker benefits at that age is declining. If the Amendments did affect SSDI enrollment through the mechanism described above, then one would expect SSDI enrollment rates at a certain age to increase more rapidly when cohorts born between 1938 and 1943 reach that age.

Using data for the 1934 through 1946 cohorts, our estimates strongly suggest that the decline in the generosity of Social Security retired worker benefits led to a significant increase in SSDI enrollment among both women and men. For each $\$ 5,000$ decline in the average present value of OA benefits, we estimate that SSDI enrollment increased by 0.6 percentage points, with the estimated effects approximately twice as large for women as for men ( 0.8 versus 0.4 percentage points). We obtain similar estimates if we restrict attention to those between the ages of 45 and 54 or between the ages of 55 and 64, though because the change in the present value increases with age, the effect on SSDI enrollment does as well. We also obtain similar estimates when we expand our analysis sample to consider individuals born between 1920 and 1960, with these estimates incorporating the effect of the second phase of the policy change described above.

In the final section of our paper, we calculate how much of the increase in SSDI enrollment from 1983 to 2005 can be explained by the reduction in the generosity of retired worker benefits. Our point estimates suggest that SSDI enrollment was 0.58 percentage points higher among men between the ages of 45 and 64 and 0.89 percentage points higher among women in this same age range in December of 2005 than it otherwise would have been. Given that the actual increases during this same period were 1.64 and 3.41 percentage points for men and women, respectively, our findings suggest that this policy change was an important contributor to the rise in SSDI enrollment. Our estimates further suggest that the effect on SSDI enrollment twenty years from now, when those who received the maximum reduction in retired worker benefits will have aged into their fifties and early sixties, will be almost twice as large than at present. 


\section{Background on the OASDI Program and the 1983 Amendments}

\section{A. Retired Worker and Disabled Worker Benefits Prior to the Amendments}

The Old Age, Survivors, and Disability Insurance (OASDI) program currently provides retirement, disability, and survivor benefits to more than 48 million U.S. residents. Payments to retired workers and their dependents accounted for more than 70 percent of program spending during the 2004 calendar year. To be eligible for retired worker benefits, an individual must be at least 62 years old and must have accumulated at least forty quarters of coverage during his or her working years. The amount of earnings necessary for each quarter of coverage is generally increasing over time, with $\$ 3680$ or more sufficient to earn four quarters during the 2005 calendar year. Thus a person with a significant amount of earnings in ten or more years would generally be eligible for retired worker benefits upon reaching the age of 62 .

The eligibility criteria are somewhat different for Social Security Disability Insurance benefits. First, a person younger than 18 or older than the full retirement age at the time she became disabled would not be eligible for disabled worker benefits. Second, the individual must have accumulated at least twenty quarters of coverage during the ten years leading up to the onset of the disability. ${ }^{4}$ Third, the person must not be engaging in substantial gainful activity, which is currently defined to be earnings in excess of $\$ 860$ per month. And finally, the individual must apply for SSDI benefits at a local Social Security Administration (SSA) field office. If the SSA determines that the individual is unable to work, then an SSDI award is made.

To determine an individual's retired worker or disabled worker benefits, the SSA first calculates her average indexed monthly earnings (AIME). For a retired worker, this is equal to the

\footnotetext{
${ }^{4}$ The number of quarters of coverage needed to be SSDI-insured is lower for younger workers.
} 
average of her 35 highest years of indexed earnings. ${ }^{5}$ The number of years used in the AIME calculation for a disabled worker is lower given that she would have fewer possible work years. For example, the SSA would use the highest 21 years of indexed earnings for an SSDI recipient disabled at the age of 47 versus 34 years for someone disabled at the age of $60 .^{6}$ The AIME is then used to compute the Primary Insurance Amount (PIA), which is the monthly Social Security benefit payable to a retired worker if they first claim benefits at the full retirement age or to a disabled worker when they begin receiving benefits at any age. The PIA formula is progressive, so that the fraction of earnings replaced by social security benefits declines as one’s AIME increases. ${ }^{7}$

Upon reaching the early retirement age of 62, insured persons have the option to claim retired worker benefits, though at a reduced rate. For individuals born in 1937 or earlier, the penalty for claiming in the month of attaining the age of 62 is 20 percent, so that the person's monthly benefit would be just 80 percent of the PIA. For each month that the person chooses to delay claiming, the penalty declines by $5 / 9$ of a percentage point, with this penalty reaching zero at the full retirement age of 65. This adjustment to benefits for claiming early was designed to be approximately actuarially fair for a person with average mortality.

The monthly Social Security benefit for an SSDI recipient is equal to 100 percent of the PIA when they are first awarded benefits and, like retired worker benefits, this benefit is indexed to inflation in subsequent years. SSDI recipients are converted to Social Security's retirement program (with the same monthly benefit) upon reaching the full retirement age.

\footnotetext{
${ }^{5}$ Taxable earnings are indexed in each year using an indexing factor, which is equal to the ratio of average wages in the year that the person reaches the age of 60 to average wages in the year considered. Earnings at ages 61 and up are not indexed. For a list of indexing factors used for each year of earnings by year-of-birth, see Table 2.A.8 in the Social Security Administration's Annual Statistical Supplement (2006).

${ }^{6}$ For SSDI recipients disabled at the age of 47 or later, the number of years used is equal to "the number of full calendar years elapsing between the age 21 and the year of first eligibility, usually excluding the lowest 5 years. Workers disabled before the age of 47 have 0 to 4 years excluded.” (SSA, 2006).

${ }^{7}$ More specifically, in 2005 the first $\$ 627$ of the AIME is replaced at 90 percent, the next $\$ 3152$ is replaced at 32 percent, and any remaining AIME is replaced at 15 percent. Only earnings that were subject to OASDI payroll taxes are considered when calculating the AIME.
} 


\section{B. The Social Security Amendments of 1983}

On April 20, 1983, the Social Security Amendments of 1983 were signed into law. The main motivation for this legislation was to improve both the short and the long-term fiscal health of the OASDI program. Included in these Amendments were a number of significant changes to social security, including an increase in the payroll tax rate, an expansion in the number of individuals covered by the program, and an increase in the actuarial adjustment factors beyond the full retirement age. Perhaps the most significant change of all, however, was a two-year increase in the full retirement age and a corresponding increase from 20 to 30 percent in the penalty for claiming retired worker benefits at the early retirement age of 62 .

These reductions in the generosity of Social Security retired worker benefits were phased in gradually and occurred in two main stages. Individuals born in 1937 or earlier were unaffected by the change. The full retirement age then increased in two-month increments by subsequent birth cohort until reaching 66 for those born in 1943, where it remained until again increasing in twomonth increments from the 1955 to 1960 cohorts. Along with this change, the fraction of full benefits that individuals could receive at the early retirement age of 62 fell from 80 percent for those born in 1937, to 75 percent for those born between 1943 and 1954, and to 70 percent for those born in 1960 or later. ${ }^{8}$ The changes in the full retirement age and in the fraction of the PIA available at the early retirement age of 62 are summarized in Figure 1.

As a result of this legislation, the generosity of OASDI retired worker benefits for individuals born in 1938 or later declined relative to what they otherwise would have been. To estimate the average impact of this policy change on retired worker benefits, we consider the case of an individual age 62 or younger who is planning to claim retirement benefits at the early retirement age of 62 , the

\footnotetext{
${ }^{8}$ This policy also changed the actuarial adjustment factors beyond the age of 62 from 5/9 of a percentage point per month to $5 / 12$ of a percentage point per month. This converted back to 5/9 of a percentage point 36 months before the full retirement age. Thus a person born in 1943 could receive 75 percent of his or her PIA at the age of 62, 80 percent at the age of 63, 86.67 percent at the age of 64, 93.33 percent at the age of 65, and 100 percent at age 66. For more details, see Table 2.A.17.1 in the 2005 Annual Statistical Supplement (SSA, 2006).
} 
most common age of claiming retired worker benefits in every year of our study period. The average change in the present value of retirement benefits for an individual at age A born in year B is as follows:

$$
\text { (1) } \Delta P V_{A, B}=R_{B} * S_{A, 62} *(1+r)^{A-62} \sum_{t=62}^{119} S_{62, t} *(1+r)^{62-t} * P I A
$$

with $S_{X, Y}$ equal to the probability of surviving from age $X$ to age $Y$ (note that $S_{62,62}=1$ and the assumption that $S_{62,120}=0$ ), $R_{B}$ equal to the percentage point reduction in early retirement benefits for individuals born in year B, r equal to the interest rate used to discount future benefits, and PIA equal to the average primary insurance amount upon reaching the age of $62 .{ }^{9}$ For this same person at age A beyond the age of 62, the change in the present value of benefits can be written as:

$$
\text { (2) } \Delta P V_{A, B}=R_{B} \sum_{t=A}^{119} S_{A, t} *(1+r)^{A-t} * P I A
$$

The key source of variation for our purposes in equations (1) and (2) arises through $\mathrm{R}_{\mathrm{B}}$, which represents the change in the generosity of retired worker benefits caused by the 1983 amendments. This ranges from a low of 0 for those born in 1937 or earlier to a high of 10 percentage points for those born in 1960 or later. As described above and in Figure 1, these increases in the penalty for claiming at the early retirement age were made in increments of 0.833 percentage points from 1938 to 1943, then remained at 5 percentage points from 1943 to 1954, and again increased in 0.833 percentage point increments from 1955 to 1960.

Of course, the average present value of retired worker benefits will vary across cohorts not only because of the 1983 Amendments. For example, mortality rates have generally been declining over time and this will tend to increase the value of benefits from one cohort to the next. Similarly the program's benefit formula is indexed to average wage growth, and thus the real value of the

\footnotetext{
${ }^{9}$ This formula does not account for variation over time in an individual's PIA. More specifically, the PIA depends partially on the age at which it is computed because, for example, different years of earnings may be used in the calculation. But this was true before and after the policy change and thus we do not attempt to model the change in the individual's PIA here.
} 
average PIA tends to increase over time. But to the extent that these changes produce a smooth trend in the value of retired worker benefits, the policy induced a decline in this trend relative to what it would have otherwise been. ${ }^{10}$

In figure 2, we plot the average policy-induced decline in the present value of retired worker benefits as a function of age for men between the ages of 45 and 64 who were born in 1939, 1941, and 1943. For these calculations, we use age-specific mortality rates for men from the SSA's Office of the Actuary, assume an annual discount rate of 3 percent, and set PIA $\mathrm{B}_{\mathrm{B}}$ equal to the average primary insurance amount for men claiming retired worker benefits in 1999, the last year in which no retired workers would have been affected by the Amendments. As the figure demonstrates, the impact of the policy was significantly lower for cohorts born in 1939 than those born in 1941 or 1943. Additionally, the impact of the policy increased with age, both because of time discounting and because of the non-trivial probability that an individual would die before reaching his or her early retirement age. The effect of the policy then declines following the $62^{\text {nd }}$ birthday, reflecting the fact that one or two years of reduced benefits would already have been received.

The variation in the policy's effect summarized in this Figure and in Table 1 increases by a factor of almost two from a 45-year old male to a 62-year old male. ${ }^{11}$ More specifically, among men born in 1943, the decline in the present value of retired worker benefits for 45 -year olds is $\$ 4716$ versus $\$ 8878$ for 62-year olds. These declines are one-third as large for the 1939 cohort and twothirds as large for the 1941 cohort. And though their changes are not summarized in this Figure, the effect of the policy for individuals born in 1960 or later would be twice as large as for those born between 1943 and 1954. To calculate these same changes for women, we use female-specific

\footnotetext{
${ }^{10}$ For example, suppose that the present value was increasing by an average of 1 percent per year up through and including the 1937 cohort. The policy will reduce this to essentially zero, given that the present value is declining more than one percent per year as a result of the policy ( 0.833 percentage points divided by 80 percentage points). ${ }^{11}$ Of course the effect of the 1983 Amendments likely varied not only across cohorts but also within cohorts. One might expect, for example, high income individuals to be less responsive than their low income counterparts to the change given that social security accounts for a much smaller share of their income (Mitchell and Phillips, 2000).
} 
mortality rates and the average PIA for women claiming retired worker benefits in 1999. At each age these declines are approximately one-third lower for women than for men. Thus despite the fact that mortality rates for women are much lower than those for men, the fact that their average PIA in 1999 is 40 percent lower more than offsets this.

\section{Previous Research}

Previous work for other government programs has suggested that reductions in the generosity of one program can lead to increases in enrollment in other programs. ${ }^{12}$ In this case, Social Security retired worker benefits were reduced while no corresponding changes were made to SSDI benefit generosity. Thus, to the extent that individuals can potentially substitute disability for retirement benefits, a policy designed to reduce spending on retired worker benefits may have inadvertently increased SSDI applications and enrollment. Since social security benefits are the major source of income for 65 percent of elderly recipients and account for more than 90 percent of income for onethird of those individuals (SSA, 2006), it seems plausible that the significant decline in the generosity of retirement benefits due to the 1983 Amendments influenced individual behavior. Policymakers did recognize that the Amendments could lead to an increase in disability enrollment, with a U.S. General Accounting Office report stating that the magnitude of this increase would depend on the responsiveness of individuals to the increased incentive to apply for SSDI (GAO, 1998). ${ }^{13}$

Recent studies, however, find little evidence to suggest that SSDI enrollment should increase significantly as a result of the 1983 Social Security Amendments. For example, Mitchell and Phillips (2000) use data from the Health and Retirement Study to estimate a choice model with three potential retirement pathways: claim at the early retirement age, claim at the full retirement age, or apply for SSDI benefits. Their parameter estimates suggest that a $\$ 25,000$ cut in the present value of Social

\footnotetext{
${ }^{12}$ See Garrett and Glied (2001), Kubik (2003), Schmidt and Sevak (2004), and Duggan and Kearney (2005)

${ }^{13}$ See Benitez-Silva et al (1999) and Hausman and Halpern (1986) for an examination of the determinants of the SSDI application decision.
} 
Security retired worker benefits ${ }^{14}$ would increase SSDI enrollment by 0.6 percentage points. They argue that this effect is small given that three times as many individuals would delay claiming Social Security retirement benefits as a result of the benefit cut. Additionally, Bound, Stinebrickner, and Waidman (2004) estimate a structural model of retirement to consider the impact of changes in the OASDI program on labor market behavior. Their simulations suggest an even smaller effect of the increase in the normal retirement on SSDI applications and enrollment.

While both of these studies make important contributions to knowledge, they do have some limitations. For example, both studies apply parameter estimates from their models to simulate the effects of reducing retirement benefits rather than using the actual changes in SSDI enrollment by birth cohort to estimate these effects. To the extent that the models do not fully capture key aspects of individual behavior, the results from these simulations could be misleading. ${ }^{15}$ Additionally both studies use a relatively small sample of individuals ${ }^{16}$ and thus even if the models were properly specified, it would be difficult to obtain precise estimates. And finally, the studies use data up through just 1998 (M,P) or 2000 (B,W,S). They are therefore unable to observe SSDI enrollment beyond the age of 60 or 62 for anyone affected by the Amendments. ${ }^{17}$

In the sections that follow, we build on this previous work by utilizing administrative data on SSDI enrollment through 2005 for a ten percent sample of the U.S. population along with an alternative identification strategy to investigate the effect of the policy-induced reduction in the generosity of retired worker benefits on SSDI enrollment.

\section{The Rise in Disability Enrollment}

\footnotetext{
${ }^{14}$ Using the average monthly retired worker benefit in 1999, this is approximately 40 percent larger than the average cut for a 62-year old even once the Amendment changes are fully phased in, as shown in Table 1.

${ }^{15}$ As Bound, Stinebrickner, and Waidman note, "the modeling approach we take is so different from the one taken by Mitchell and Phillips that it is hard to know what to attribute differences to."

${ }^{16}$ The sample sizes used to estimate the models are 196 for Bound et al and 1544 for Mitchell and Phillips.

${ }^{17}$ In related work, Gustman and Steinmeier (2005) estimate a structural model that considers the effect of an increase in the early retirement age on behavior, including application for SSDI benefits.
} 
The fraction of non-elderly adults receiving Social Security Disability Insurance benefits has risen substantially since the 1983 Social Security Amendments. When this legislation was enacted, 4.5 percent of those between the ages of 45 and 64 were receiving benefits and enrollment had actually been declining. But since the passage of the Amendments, the rate of SSDI enrollment in this age range has increased by 50 percent, with 6.7 percent of adults aged 45 to 64 on SSDI in December of 2005. The enrollment growth has been similarly striking for younger workers, with the fraction of individuals between the ages of 25 and 44 receiving SSDI benefits increasing from 0.7 to 1.6 percent. As a result of these increases, the fraction of Social Security spending accounted for by SSDI rose from 10 percent in 1983 to more than 17 percent by 2005.

\section{A. Why Has SSDI Enrollment Increased?}

Several factors have contributed to the increase in SSDI receipt. ${ }^{18}$ First, because the rate of SSDI receipt rises with age, the aging of the baby boom cohorts has contributed to the growth. But as Figures 3A and 3B demonstrate, the fraction of both men and women receiving SSDI has increased substantially at every age between 45 and 64. For example, in 1983 the fraction of 55-year old men receiving SSDI stood at 5.8 percent, but this increased to 7.5 percent by 2005 . The corresponding rise for 55-year old women was even more striking, with enrollment for them increasing from 2.6 to 6.2 percent. The larger growth in SSDI enrollment among women is partly attributable to a second important contributing factor, the rise in female labor force attachment, which has increased the fraction of women who are insured for SSDI benefits.

A third factor that has contributed to the growth in SSDI enrollment was a liberalization of the program's medical eligibility criteria implemented in 1984, which made it easier for individuals with more subjective conditions such as mental disorders, back pain, and arthritis to qualify for the program. Perhaps partly as a result, the number of awards per SSDI insured person with these

\footnotetext{
${ }^{18}$ Most previous work on SSDI has examined the program's effect on labor supply rather than the determinants of its growth. See for example Parsons (1980, 1991), Bound (1989, 1991), and Bound and Burkhauser (1999).
} 
diagnoses more than tripled from 1983 to 2003 while there was no corresponding change for conditions that are easier to verify such as cancer, heart attacks, and stroke. SSDI enrollment also increased during this period because of an increase in the replacement rate (the ratio of potential benefits to earnings) for low-skilled workers. This resulted from the interaction between a rise in income inequality and the progressive benefit formula described above. And finally, the recessions of both 1991 and 2001 led to a significant increase in the number applying for and ultimately receiving SSDI benefits. ${ }^{19}$

\section{B. Changes in SSDI Enrollment by Birth Cohort}

The 1983 Social Security Amendments increased the incentive for individuals to apply for the SSDI program by reducing the generosity of retired worker benefits. Individuals born in 1937 or earlier were unaffected by these Amendments, with the effect on an individual born later depending on her year-of-birth. The increase in the full retirement age and in the penalty for claiming benefits at the early retirement age of 62 for those born between 1943 and 1954 was twice as large as for their counterparts born in 1940 and six times as large as for a person born in 1938.

If the declining generosity of retired worker benefits did influence SSDI enrollment, one would expect - all else equal - individuals born in a year such as 1943 to be significantly more likely to receive SSDI benefits than individuals born in earlier years. To shed light on this issue, Figure 4A displays rates of SSDI enrollment for men between the ages of 60 and 64 by birth cohort. ${ }^{20}$ As the figure shows, the rates in this age range are generally increasing with year-of-birth. For example, the rate of SSDI enrollment increases from 12.7 percent among those born in 1937 to 13.6 percent for men born in 1943. The differences displayed in Figure 4B for 62-year old women are even larger, with their enrollment rate increasing from 7.9 to 10.2 percent from the 1937 to the 1943 birth cohort.

\footnotetext{
${ }^{19}$ See Rupp and Stapleton (1985), Gruber and Kubik (1997), Kreider (1997), Gruber (2000), Black, Daniel, and Sanders (2002), Autor and Duggan (2003), and Duggan and Imberman (2006) for an examination of the effect of screening stringency, the replacement rate, economic conditions, or demographic factors on disability enrollment. ${ }^{20}$ Because 2005 is our most recent year of data, the rate at the ages of 63 and 64 are missing for the 1943 cohort.
} 
Of course part of this increase could simply represent the continuation of a pre-existing trend in SSDI enrollment. To explore this possibility, Figures 5A and 5B display rates of SSDI enrollment by birth cohort for 62-year old men and women, respectively. The first of these figures shows that enrollment among men was actually declining with year-of-birth prior to 1937 . More specifically, the fraction of 62-year old men on SSDI fell from 13.0 to 12.7 percent from 1934 to 1937 . And while for women there was a positive pre-existing trend prior to the 1938 birth cohort, the annual increase of 0.38 percentage points from 1937 to 1943 was more than twice as large as the corresponding increase of 0.17 percentage points from 1934 to 1937.

Thus the enrollment trends for both men and women at the age of 62 strongly suggests that individuals born in 1938 and later were significantly more likely to receive SSDI benefits than their counterparts born in earlier years and that this effect steadily increased in each year through the 1943 cohort. But even these trends do not rule out the possibility that some factor other than the 1983 Amendments is the main explanation for the break in trend. For example, perhaps macroeconomic conditions deteriorated sufficiently after 1999 to induce a rise in SSDI enrollment. If this were true, then this could be at least partially responsible for the SSDI enrollment increase among 62-year olds that began in 2000 .

But interestingly, as Figures 5C and 5D show, the same pattern with year-of-birth emerges for these cohorts a decade earlier. For example, SSDI enrollment among 52-year old men declined from 4.5 to 4.3 percent from the 1934 to the 1937 cohort and then steadily increased to 5.5 percent for the 1943 cohort. The rate of SSDI enrollment for the 1946 cohort, whose retirement benefit reduction was identical to the 1943 cohort's, was also 5.5 percent. This figure and the corresponding one for women are consistent with the hypothesis that the 1983 Social Security Amendments increased SSDI enrollment. In the next section we outline our strategy for probing more systematically on the magnitude of this effect. 


\section{Identification Strategy}

The 1983 Amendments reduced the present value of retired worker benefits for individuals born in or after 1938. As Figures 2A and 2B demonstrate, the average dollar impact of this change varied substantially with both age and year-of-birth. For individuals choosing between alternative pathways to retirement, the Amendments reduced the attractiveness of claiming retired worker benefits. Given that there were no corresponding changes to SSDI benefits, some individuals may have responded to the change by applying for SSDI, thereby pursuing an alternative path to retirement. This change in behavior could occur long before the age of 62 if individuals were forward-looking and recognized the increase in the relative attractiveness of SSDI benefits. If instead individuals were myopic, they might only react to the policy once they were very close to or had already reached the early retirement age, when they might be more likely to carefully compare the difference between retired and disabled worker benefits.

If the Amendments did lead a substantial number of individuals to apply for and ultimately enroll in the SSDI program, one would expect to observe an increase in age-specific rates of enrollment as the 1938 and later birth cohorts reached each age. To accurately measure this effect, it is important to control for trends in SSDI enrollment, which could be changing for reasons unrelated to the Amendments. These pre-existing trends were especially apparent for women in Figures 5B and 5D, with this trend perhaps partly driven by the steady increase in female labor force attachment that made more women potentially SSDI eligible. Additionally, it is important to control for macroeconomic and other common factors that could exert an effect on SSDI enrollment at all ages.

Given these issues, we estimate models of the following type when testing for an effect of the 1983 Amendments on the fraction of individuals receiving SSDI benefits:

$$
\text { (3) } \Delta S S D I_{A, t}=\alpha_{t}+\beta * \Delta P V R_{A, t}+\mu_{A}+\varepsilon_{A t}
$$


In this equation, $\Delta \mathrm{SSDI}_{\mathrm{A}, \mathrm{t}}$ is equal to the change in the fraction of individuals at age $\mathrm{A}$ in year $\mathrm{t}$ receiving SSDI benefits. SSDI enrollment is reported by SSA as of December in each year, and thus the year-of-birth for individuals of age $\mathrm{A}$ in year $\mathrm{t}$ would be t-A. We use age and gender-specific population data from the U.S. Census Bureau and from the National Center for Health Statistics as the denominator when calculating these rates. ${ }^{21}$ We include year effects in this model $\left(\alpha_{t}\right)$ to control for common factors such as changes in macroeconomic conditions that might influence SSDI enrollment in each year and age effects $\left(\mu_{\mathrm{A}}\right)$ to control for age-specific trends in SSDI enrollment. ${ }^{22}$

Our key explanatory variable is $\Delta \mathrm{PVR}_{\mathrm{A}, \mathrm{t}}$, which represents the average change in the present value of Social Security retired worker benefits at age A in year t induced by the Amendments. This is set equal to zero if birth cohorts t-A and t-A-1 have the same generosity of retired worker benefits. For example, in 1987 this first difference would be equal to zero for 50-year olds because it would represent the difference in generosity between the 1936 and 1937 cohorts, both of which had a full retirement age of 65 and received 80 percent of full benefits when claiming at the age of 62 . However in 1988 it is negative, as the generosity of retired worker benefits is significantly lower for the 1938 cohort than for their predecessors born in 1937. More specifically, using equation (1) from above, the present value of retired worker benefits is $\$ 786$ lower for the 1938 cohort of men than for their 1937 counterparts and $\$ 592$ lower for women born in 1938 than those born in $1937 .{ }^{23}$ As Table 1 demonstrates, these amounts increase in magnitude with age until the age of 62, at which point they decline somewhat in each year given that one or more year of benefits would already have been received (assuming early claiming at the age of 62 as in equation (2) above).

\footnotetext{
${ }^{21}$ See the Data Appendix for a description of our data sources.

${ }^{22}$ Our approach is similar in spirit to Attanasio and Brugiavini (2003), who estimate the effect of a change in Italy's Social Security program on household savings. Like the 1983 Social Security Amendments in the U.S., the magnitude of the change in Italy's social security benefits depended partially on individuals' year-of-birth.

${ }^{23}$ Thus for 50-year olds the value of $\Delta \mathrm{PVR}_{\mathrm{A}, \mathrm{t}}$ would be 0 in 1985,1986 , and 1987, would equal -.932 for men and .695 for women in each year between 1988 and 1993, and would then equal 0 in 1994, 1995, and 1996. The variable is defined similarly at other ages, though the size of $\mathrm{PVR}_{\mathrm{A}, \mathrm{t}}$ in the treatment years varies as shown in Table 1.
} 
If properly estimated, the parameter $\beta$ from equation (3) represents the average effect of Social Security retired worker benefit generosity on SSDI enrollment. As described above, the 1983 Amendments reduced the generosity of retired worker benefits in two main stages. Because those affected by the latter set of changes were relatively young in 2005, our most recent year of data, we begin by focusing on the first set of changes, which were phased in from the 1938 to the 1943 birth cohorts. To do this we restrict consideration to the 1934 to 1946 birth cohorts, which gives us up to twelve first differences at every age. The first three of these are for the 1934 to 1937 cohorts and thus prior to the change in retired worker benefits and the last three are for the 1943 to 1946 cohorts and thus after these changes have been phased in.

The main advantage of considering a relatively small number of cohorts is that in each year the ages that we consider are fairly similar. For example, as shown in Table 2, in 1995 the treatment group consists of individuals between the ages of 52 and 57, while the control group includes people between the ages of 49 and 51 and between 58 and 60. Our model essentially tests whether in this year and in the 21 other years after the 1983 Amendments, SSDI enrollment increases more rapidly for those in the treatment group in each year than for their counterparts in the control group. By considering a more homogeneous group in every year, it is more likely that any unobserved factors that might influence SSDI enrollment would have a similar effect on our treatment and control groups, which is an important assumption of our model. We later expand the size of our analysis sample by considering individuals born as early as 1920 and as late as 1960 .

We further restrict attention to individuals between the ages of 45 and 64 . Our primary reason for doing this is that, as Table 2 demonstrates, this restriction ensures that we have at least four "treatment" changes at each age. ${ }^{24}$ It also seems reasonable given both that the change in the

\footnotetext{
${ }^{24}$ If we included 40 -year olds, for example, then there would be no treatment changes at this age given our definition because the 1983 to 1984 change reflects the difference between the 1943 and 1944 birth cohorts, both of which had a full retirement age of 66 and an early retirement penalty of 25 percent. Despite this, there may still have been a policy-induced increase at his age from 1983 to 1984 because of the lag in the SSDI application process.
} 
present value of benefits was lower for younger workers and that their baseline rates of SSDI enrollment were several times lower as well. ${ }^{25}$

\section{Empirical Results}

Our first main set of results is summarized in Table 3, with columns 1 through 4 providing the results from specifications similar to (3) for men and the next four columns displaying the analogous results for women. The unit of observation in every case is the change in the fraction of either men or women receiving SSDI at a certain age from one year to the next. All specifications include age effects to control for different trends across age groups in SSDI enrollment. We also include year effects to control for factors such as macroeconomic conditions that might influence SSDI enrollment from one year to the next.

In this table, we report coefficient estimates for our key explanatory variable $\Delta \mathrm{PVR}_{\mathrm{A}, \mathrm{t}}$, which is equal to the average change (in thousands of dollars) in the present value of retired worker benefits at each age. This variable has a mean of -0.600 and a standard deviation of 0.579 for men in our analysis sample, with the corresponding statistics for women at -0.440 and 0.422 . The ages that serve as both treatment and control groups in these regressions are listed in Table 2. As this table shows, there are 215 first differences that we consider over a 22 year period, with 116 of these in the treatment group and 99 in the control group. It is important to emphasize that the intensity of treatment varies with age, with the change in the present value being much larger for the average 62year old than for the average 45-year old.

In column 1 of Table 3, we report results for the effect of changes in Social Security retired worker benefits on SSDI enrollment among men between the ages of 45 and 64 . The statistically significant estimate of -.0778 suggests that each $\$ 5000$ reduction in the present value of Social

\footnotetext{
${ }^{25}$ To the extent that the 1983 Social Security Amendments also influenced SSDI enrollment for individuals between the ages of 18 and 44, we are likely to understate the overall effect of the policy below.
} 
Security retired worker benefits induces a 0.39 percentage point increase in SSDI enrollment. ${ }^{26}$ Given that the present value effects of the policy are increasing with age, this implies a smaller increase in enrollment at younger ages. For example, $\$ 5000$ is approximately equal to the change in the present value from the 1937 to the 1943 cohort for a 47-year old man. Thus if correct, our estimates imply a 0.39 percentage point increase from this first part of the policy change. However, the implied effect in SSDI enrollment for 62-year olds is almost twice as large.

In the specifications summarized in columns 2 through 4, we test whether the effect of this policy varies by age. The estimated effect of -.1066 summarized in column 2 for 45 to 54 -year olds is slightly greater than the corresponding estimate of -..0736 for 55 to 64 year old men in column 3 . Both of these estimates are statistically significant. In the fourth column we include all ages but interact $\triangle \mathrm{PVR}_{\mathrm{A}}$, with an indicator for whether this cell is between the ages of 55 and 64 . While the estimate for this interaction is positive, it is not statistically significant. Thus one cannot conclude from these estimates that younger individuals are more or less responsive to the policy change.

In the next four columns we present an analogous set of estimates for women. The statistically significant coefficient estimate of -.1639 in column 5 is more than twice as large as the corresponding estimate for men from column 1. But because the effect of the Amendments on the average present value of retired worker benefits was considerably lower for women than for men, the implied effect on overall SSDI enrollment is not twice as large, as we show in the next section. One possible explanation for the greater responsiveness among women is that their baseline rates of labor force participation are significantly lower throughout our study period. This would imply that more women than men could respond to the policy by applying for SSDI without having to first leave their

\footnotetext{
${ }^{26}$ When estimating these models, we account for the fact that the policy's effect varies with year-of-birth by using the Stata ${ }^{\mathrm{TM}}$ cluster command and clustering by year-of-birth. Recent econometric evidence suggests that clustering may be problematic when the number of clusters is smaller than approximately 50. In our final set of specifications we consider 41 birth cohorts and obtain similar results.
} 
job. Interestingly, the results in columns 6 through 8 suggest that older women are somewhat more responsive to the policy change, though the difference is not statistically significant. ${ }^{27}$

We next pool rates of SSDI enrollment for men and women and present an analogous set of specifications for all individuals in columns 1 through 3 of Table 4. Our explanatory variable here is simply the average of the change in the present value for women and men. Not surprisingly, our estimates in each case lie between the estimates for men and women. For example, the estimated effect of -.1151 is approximately the average of the corresponding estimates of -.0778 and -.1639 for men and women, respectively. In this case the estimates for younger and older individuals are almost identical, as shown in columns 2 and 3.

One possible concern with this first set of estimates is that they rely exclusively on the first part of the Amendments, which were phased in across the 1938 to 1943 cohorts. In the next specification we present the results from an analogous specification in which we consider only the second change, which was phased in from 1954 to $1960 .^{28}$ To preserve consistency with the first set of estimates, we consider 13 birth cohorts, though in this case we use only “pre-treatment” birth cohorts (born from 1948 to 1954) given that no "post-treatment” cohorts had yet reached the age of 45 by 2005. Our estimated effect for this latter policy is similar to those for the initial one, though the standard errors are considerably larger as well. This is presumably because we have fewer observations and because the variation in $\Delta \mathrm{PVR}_{\mathrm{A}, \mathrm{t}}$ is smaller given that the treated individuals are relatively young. In any case, this negative point estimate provides suggestive support for an effect of retired worker benefit generosity on SSDI enrollment.

\footnotetext{
${ }^{27}$ Our results are very similar if we instead use an annual discount rate of 2 or 4 percent when calculating the present value of retired worker benefits. Of course they would also be very similar if we used the average PIA from a different year (instead of 1999), as this would simply multiply our current values of $\Delta \mathrm{PVR}_{\mathrm{T}, \mathrm{A}}$ by a common factor. ${ }^{28}$ For this change, we observe 6 years of the treatment for 45 year olds (first differences from 2000 to 2005 for cohorts 1955-60), 5 years for 46 year olds (2001 to 2005), four years for 47 year olds (2002 to 2005), three years for 48 year olds (2003 to 2005), two years for 49 year olds (2004 to 2005), and one year for 50 year olds (2005).
} 
In the next three columns we merge these two groups (along with the 1946-47 and 1947-48 first differences) and thus simultaneously consider 27 birth cohorts. Our estimates for the effect of SSDI benefits are slightly smaller than are the ones for the first part of the policy though they remain statistically significant. When we differentiate between those between the ages of 45 and 54 and their counterparts aged 55 to 64, our estimates suggest an effect that is approximately 50 percent greater for older workers. Estimates for both age groups remain statistically significant.

In the final specification, we consider individuals between the ages of 45 and 64 in every year between 1984 and 2005. By doing this, we consider 41 birth cohorts, those born between 1920 and 1960. Our point estimate from column 5 is virtually unchanged, though the standard error rises slightly and thus our estimates there are significant at just the ten percent level.

It is worth emphasizing that our finding that individuals responded to the reduction in retirement benefits long before reaching the early retirement age strongly suggests both that they are forward-looking and - if they left their jobs as a result of the policy change to apply for SSDI - that they are not liquidity constrained. ${ }^{29}$ If individuals were forced to live on current income because they were liquidity constrained, they would not have the flexibility to respond to the reduction in future retirement benefits by leaving their job in order to apply for SSDI benefits. An important avenue for future work would be to calibrate a life cycle model to determine which individuals would be most likely to respond to the 1983 Social Security Amendments by applying for SSDI and at what point in their life cycle these responses would be most likely to occur. ${ }^{30}$

Taken together, the results presented in this section combined with the graphical evidence from the preceding section strongly suggest that the reduction in the generosity of Social Security

\footnotetext{
${ }^{29}$ It is of course possible that many of the individuals who applied for and ultimately received SSDI as a result of the policy change were already unemployed or out of the labor force. In other words, the finding that the policy increased SSDI enrollment does not necessarily imply that those who responded would otherwise have been working.

${ }^{30}$ See Card, Chetty, and Weber (2006) for a recent example for the case of unemployment insurance in Austria. In this paper the authors calibrate and test several different intertemporal models.
} 
retired worker benefits caused by the 1983 Social Security Amendments led to a significant increase in SSDI enrollment. While the confidence intervals surrounding our estimates are compatible with a wide range of effects, this policy seems to have made an important contribution to the steady growth in SSDI enrollment during the past two decades. In the next section, we explore how much of the growth in enrollment can be explained by the Amendments and what the long-run effect will be on the program given that its effects will not be fully felt until those born in 1960 reach their full retirement age in 2027. At that point, all adults between the ages of 18 and 66 would have a full retirement age of 67 and a maximum early retirement penalty of 30 percent.

\section{The Contribution of the 1983 Amendments to the Rise in SSDI Enrollment}

By December of 2005, the changes made by the 1983 Social Security Amendments had reduced the present value of retired worker benefits for all non-elderly adults. The magnitude of this change varied with age, with much of this variation attributable to the policy not yet being fully phased in for older workers. For example, individuals who were 62 years old in 2005 were born in 1943 and thus were exposed to just the first half of the reduction in benefit generosity, with their early retirement penalty and full retirement age at 25 percent and 66 years old, respectively. However, their counterparts born in 1960 were fully affected by the Amendments, with an early retirement penalty of 30 percent and a full retirement age of 67 . Thus as Table 2 demonstrates, the average reduction in retired worker benefits was larger for 45 year olds (\$9432 for men and \$7104 for women) than for 62 year olds (\$8878 for men and $\$ 6348$ for women). The smallest changes in benefits were present for 64-year olds, who were exposed to just one-third of the eventual reduction in benefit generosity because they were born in $1941 .^{31}$

\footnotetext{
${ }^{31}$ The benefit reduction is also smaller for them than for 62-year olds because they would already have received one or two years of benefits, which would thus not be included in the calculation.
} 
To estimate the contribution of the 1983 Social Security Amendments to the rise in SSDI enrollment during our study period, we multiply these changes in retired worker benefits at each age by our gender-specific point estimates for the effect of these changes from Table $3 .{ }^{32}$ Specifically we use the estimate of -.0778 from specification 1 for men and -.1639 from specification 5 for women. We report both our estimates for the policy's effect on age-specific SSDI enrollment and the actual change in SSDI enrollment during our study period in the columns with the headings FRA Impact and Actual $\Delta$, respectively.

The results presented in Table 5 suggest that the 1983 Social Security Amendments had a substantial effect on SSDI enrollment. For example, our estimates suggest that the policy increased enrollment by 0.52 percentage points among 55-year old men versus an actual change of 1.77 percentage points. The corresponding estimate for 55-year old women is 0.81 percent versus an actual change of 3.54 percentage points. In general, while the implied effects for women are larger than those for men at every age, they explain a smaller share of the increase for women. For 55-year old adults, the effect of the reduction in retired worker benefits can explain 29 percent of the growth in SSDI enrollment for men versus 23 percent for women.

In the final row of this table, we estimate the impact of the policy change on overall SSDI enrollment among 45 to 64-year old men and women. In doing this, we use the age distribution for both genders in December of 2005. Our estimates there suggest that the retired worker benefit changes caused by the 1983 Social Security Amendments increased SSDI enrollment among men by 0.58 percentage points and among women by 0.89 percentage points. When compared with the actual increases, our estimate suggests that the policy change can explain 35 percent of the increase in SSDI enrollment among men between the ages of 45 and 64 and 26 percent for women.

\footnotetext{
${ }^{32}$ Here we neglect the mechanical effect of the Amendments on SSDI enrollment, which occurs because there will now be some 65 and 66 year old individuals on the program. Absent the Amendments, an SSDI recipient would shift to retired worker benefits on her $65^{\text {th }}$ birthday.
} 
Additionally, our findings suggest that the number of non-elderly individuals receiving SSDI benefits was 568,000 greater in late 2005 than it would have been in the absence of the Amendments.

In the final column for both men and women, we estimate the long-run effect of the reduction in retired worker benefits on SSDI enrollment. This represents our estimate of the effect in 2024 and all subsequent years, when all individuals between the ages of 45 and 64 would have a full retirement age of 67 and an early retirement penalty of 30 percent. To do this we first calculate the change in the present value of benefits assuming that the policy has been fully phased in. This was already true for 45-year olds by 2005, but for all other ages the policy had been just partially phased in. For example, those between the ages of 51 and 62 had been "treated" with just half of the policy by 2005 and 64-year olds had been "treated" with just one-third of the policy change. Thus our estimate of the long-run effect for 64-year olds is three times greater than the estimated effect in 2005.

Our estimate for the long-run effect of the policy on SSDI enrollment for men and women between the ages of 45 and 64 is reported in the final row of the Long-Run columns. The estimates of 1.00 percentage points for men and 1.56 percentage points for women are approximately 75 percent greater than the analogous estimated effects as of 2005. It therefore appears that the reduction in the generosity of retired worker benefits caused by the 1983 Social Security Amendments will contribute almost as much to SSDI enrollment during the next two decades as it has during the past two decades.

\section{Conclusion}

The primary goal of the 1983 Social Security Amendments was to increase the short and long-term fiscal health of the OASDI program. Perhaps the most significant change resulting from this legislation was a reduction in the generosity of Social Security retired worker benefits. No corresponding changes were made to disabled worker benefits. Our findings in this paper suggest that one important effect of this legislation was an increase in the number receiving SSDI benefits. 
More specifically, we find that the Amendments can explain more than one-third of the increase in SSDI enrollment among men since 1983 and more than one-fourth of the increase among women during this same period. Because the reductions in benefit generosity have not yet been fully phased in, the long-run effect on SSDI enrollment will be almost twice as large.

These results suggest that any changes to Social Security retired worker benefits may have important spillover effects to the SSDI program. In the case considered here, part of the reduction in spending for Social Security retired worker benefits was offset by an increase in spending on disabled worker benefits. Recent proposals to reform Social Security, such as those presented by the President's Commission in 2001, have largely ignored the SSDI program. The findings presented in this paper suggest that policymakers may want to incorporate SSDI when considering how optimally to reform the U.S. Social Security program.

In this paper we have explored just one response to the 1983 Social Security Amendments, though this legislation may have had other important effects as well. For example, reductions in the actuarial adjustment factors beyond the age of 62 may have changed individuals’ optimal timing for claiming social security retired worker benefits. Similarly, by reducing the present value of Social Security retirement wealth, the legislation may have affected individuals’ optimal labor supply and savings decisions. More work on the effect of this legislation, which represented one of the most important set of changes to Social Security since its inception more than seventy years ago, is clearly warranted. 


\section{Data Appendix}

SSDI Enrollment data by single year of age and gender for the 1983-2004 calendar years were obtained from the Social Security Administration's Annual Statistical Supplement. In producing this data, the SSA uses a ten percent sample of the Master Beneficiary Record (MBR). This same data was tabulated for December of 2005 using the full MBR. For the December 2004 data see http://www.ssa.gov/policy/docs/statcomps/supplement/2005/5a.pdf

Population data by single year of age and gender for the 1990-2005 calendar years was obtained from the National Center for Health Statistics' "U.S. Census Populations with Bridged Race Categories," which can be found at http://www.cdc.gov/nchs/about/major/dvs/popbridge/popbridge.htm

Population data by single year of age and gender for the 1983-1989 calendar years was obtained from the U.S. Census Bureau's quarterly population estimates, which can be found at http://www.census.gov/popest/archives/1980s/

Population data were reported as of July 1 in each year. We therefore took the average of the values in year $t$ and year $t+1$ to estimate the population in December of year $t$. To estimate the population data in December of 2005, we multiplied the July 1, 2005 estimate for age A by the ratio of the population at age A-1 on July 1, 2005 to the population at age A-1 on July 1, 2004.

Mortality rate estimates by gender and age were obtained from the Social Security Administration's Office of the Actuary. This data can be found at http://www.ssa.gov/OACT/STATS/table4c6.html The mortality data used in this paper were updated by SSA on June 27, 2006. 


\section{$\underline{\text { References }}$}

Attanasio, O., Brugiavini A., 2003. “Social Security and Households’ Saving.” Quarterly Journal of Economics 118 (3), 1075-1119.

Autor, D., Duggan, M., 2003. “The Rise in the Disability Rolls and the Decline in Unemployment.” Quarterly Journal of Economics 118(1): 157-205.

Autor, D., Duggan M., 2006. "The Growth in the Social Security Disability Rolls: A Fiscal Crisis Unfolding.” Journal of Economic Perspectives, Summer, 2006.

Benitez-Silva, H, Buchinsky M., Chan H., Rust J., Sheidvasser S., 1999. "An Empirical Analysis of the Social Security Disability Application, Appeal, and Award Process," Labour Economics, 6, 147-178.

Black, D., Daniel, K., Sanders, S., 2002. “The Impact of Economic Conditions on Participation in Disability Programs: Evidence from the Coal Boom and Bust.” American Economic Review, 27-50.

Bound, J., 1989. “The Health and Earnings of Rejected Disability Insurance Applicants.” American Economic Review, 482-503.

Bound, J., 1991. “The Health and Earnings of Rejected Disability Insurance Applicants: Reply.” American Economic Review, 1427-1434.

Bound, J., and R. Burkhauser. 1999. "Economic Analysis of Transfer Programs Targeted on People with Disabilities,” in Orley Ashenfelter and David Card, eds., Handbook of Labor Economics, Volume 3 (Amsterdam: North-Holland).

Bound, J., Stinebrickner T., Waidman T., 2004. "Using a Structural Retirement Model to Simulate the Effect of Changes to the OASDI and Medicare Programs." University of Michigan Retirement Research Center Working Paper.

Card, D., Chetty, R., Weber, A., 2006. "Cash-on-Hand and Competing Models of Intertemporal Behavior: New Evidence from the Labor Market," UC-Berkeley mimeo, 2006.

Duggan, M., Imberman S., 2006. "Why are the DI Rolls Skyrocketing? The Contribution of Population Characteristics, Economic Conditions, and Program Generosity,” forthcoming in D. Cutler and D. Wise, eds., Health in Older Ages: The Causes and Consequences of Declining Disability among the Elderly.

Duggan, M., Kearney M., 2006. “The Impact of Child SSI Enrollment on Household Outcomes: Evidence from the SIPP.” NBER Working Paper.

Garrett, B., Glied, S., 2000. “Does State AFDC Generosity Affect Child SSI Participation?” Journal of Policy Analysis and Management, 275-95.

Gruber, J., 2000. “Disability Insurance Benefits and Labor Supply.” Journal of Political Economy, 1162-1183. 
Gruber, J., Kubik J., 1997. "Disability Insurance Rejection Rates and the Labor Supply of Older Workers.” Journal of Public Economics, 1-23.

Gustman, A., Steinmeier T., 2005. “The Social Security Early Entitlement Age in a Structural Model of Retirement and Wealth.” Journal of Public Economics, 441-463.

Hausman, J., Halpern J., 1986. “Choice under Uncertainty: The Decision to Apply for Disability Insurance.” Journal of Public Economics. 131-161.

Kreider, B., 1999. "Social Security Disability Insurance: Applications, Awards, and Lifetime Income Flows.” Journal of Labor Economics, 784-827.

Kubik, J., 2003. "Fiscal Federalism and Welfare Policy: The Role of States in the Growth of Child SSI.” National Tax Journal, 61-79.

Mitchell, O., Phillips J., 2000. "Retirement Responses to Early Social Security Benefit Reductions.” NBER Working Paper No. 7963.

Parsons, D., 1980. “The Decline of Male Labor Force Participation.” Journal of Political Economy, 117-134.

Parsons, D., 1991. “The Health and Earnings of Rejected Disability Insurance Applicants: Comment.” American Economic Review, 1419-1426.

Rupp, K., Stapleton, D., 1995. "Determinants of the Growth in the Social Security Administration’s Disability Programs: An Overview.” Social Security Bulletin, 43-70.

Schmidt, L., Sevak, P., 2004. “AFDC, SSI, and Welfare Reform Aggressiveness: Caseload Reductions vs. Caseload Shifting." Journal of Human Resources 39(3): 792-812.

U.S. General Accounting Office, 1998. "Social Security Reform: Raising Retirement Ages Improves Program Solvency but May Cause Hardship for Some." Testimony before the Special Committee on Aging, United States Senate. Washington, D.C.

U.S. Social Security Administration. Various years. Annual Statistical Supplement to the Social Security Bulletin. Office of Research, Evaluation, and Statistics. 
Figure 1: Social Security Retired Worker Benefit Generosity by Year-of-Birth

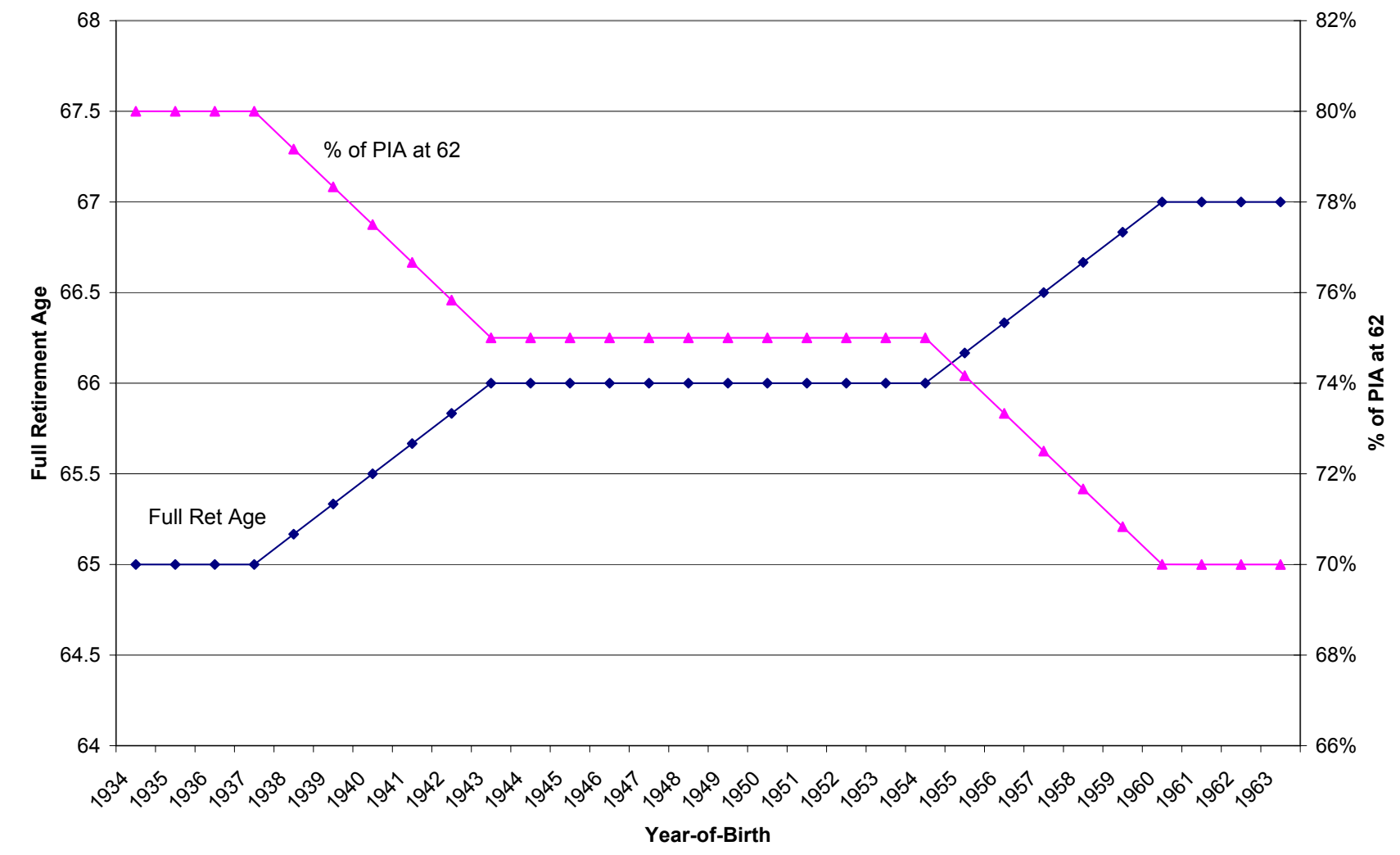

Figure 2: Average Decline for Men in PV of Retired Worker Benefits by Age and Year-of-Birth

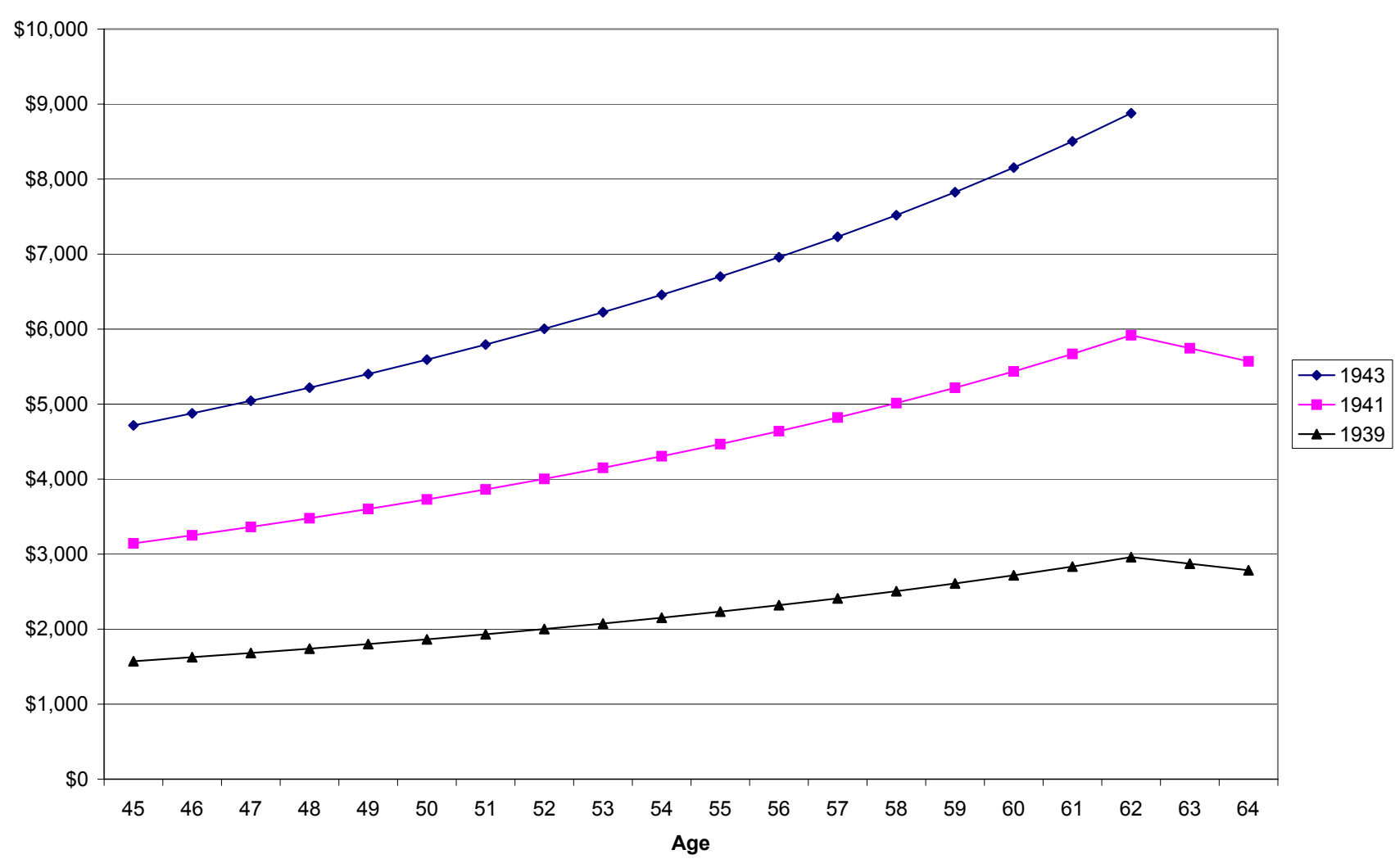




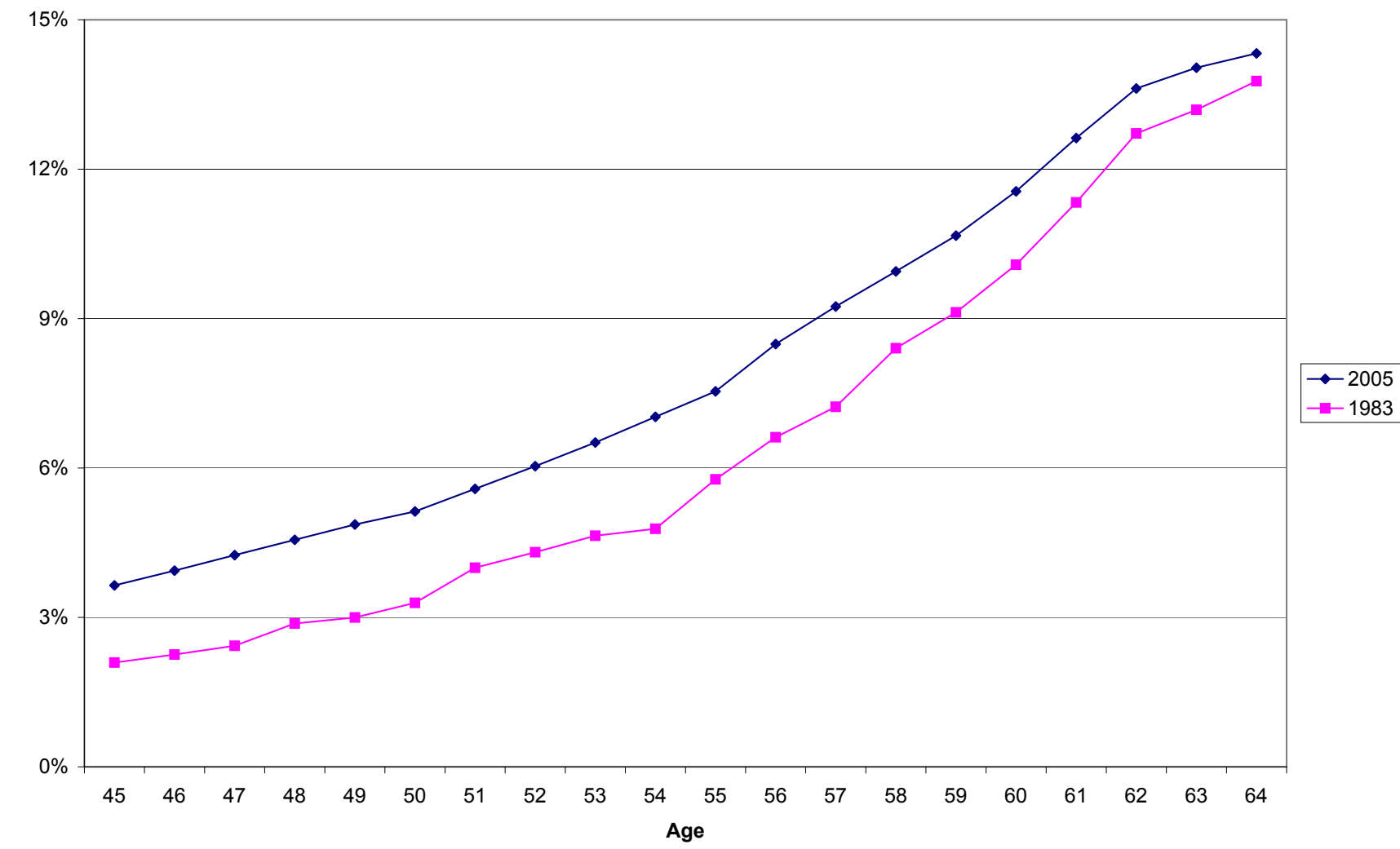

Figure 3B: Percent of Women Receiving SSDI by Age in 1983 and 2005

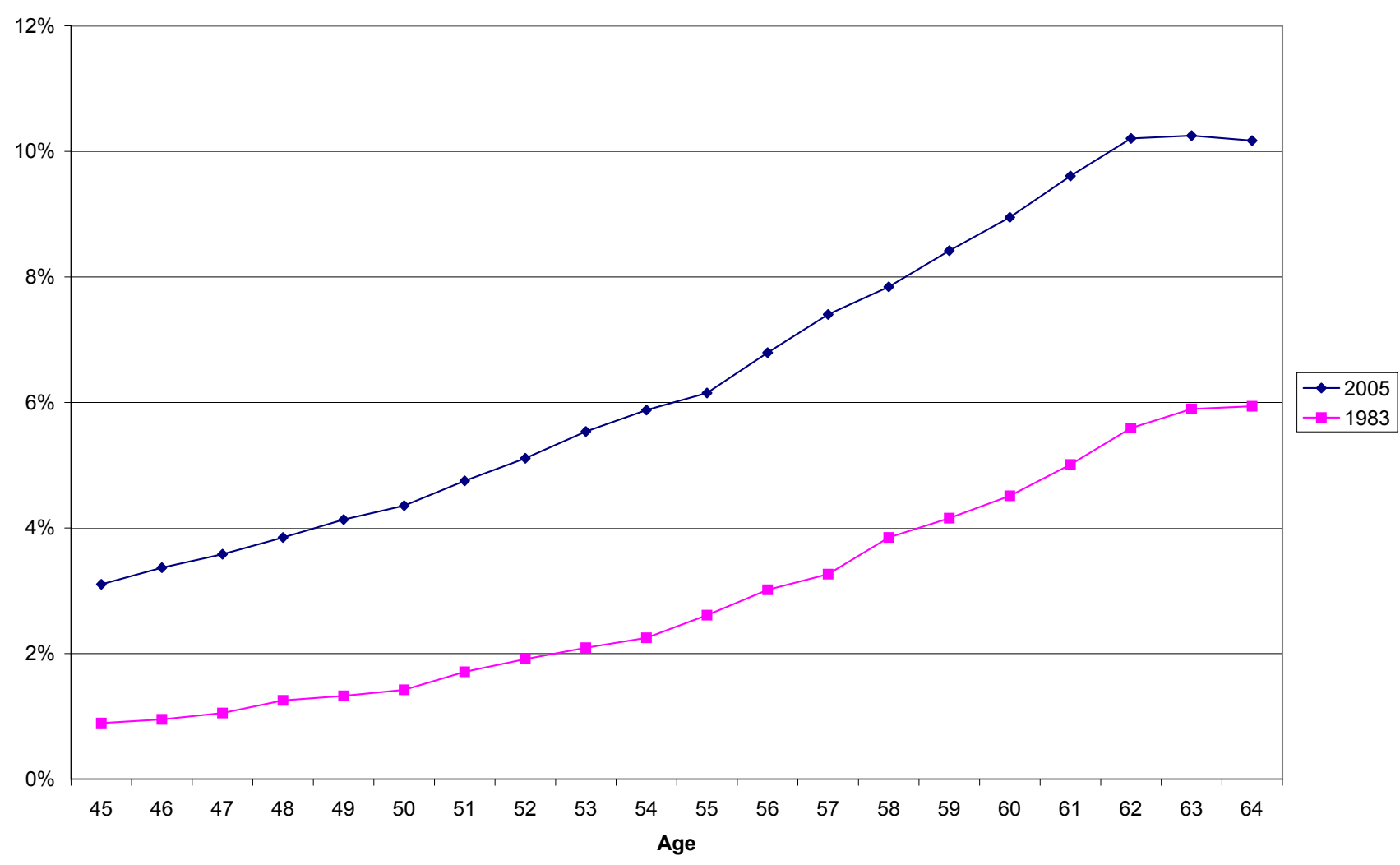


Figure 4A: Percent of Men Receiving SSDI by Age and Year-of-Birth

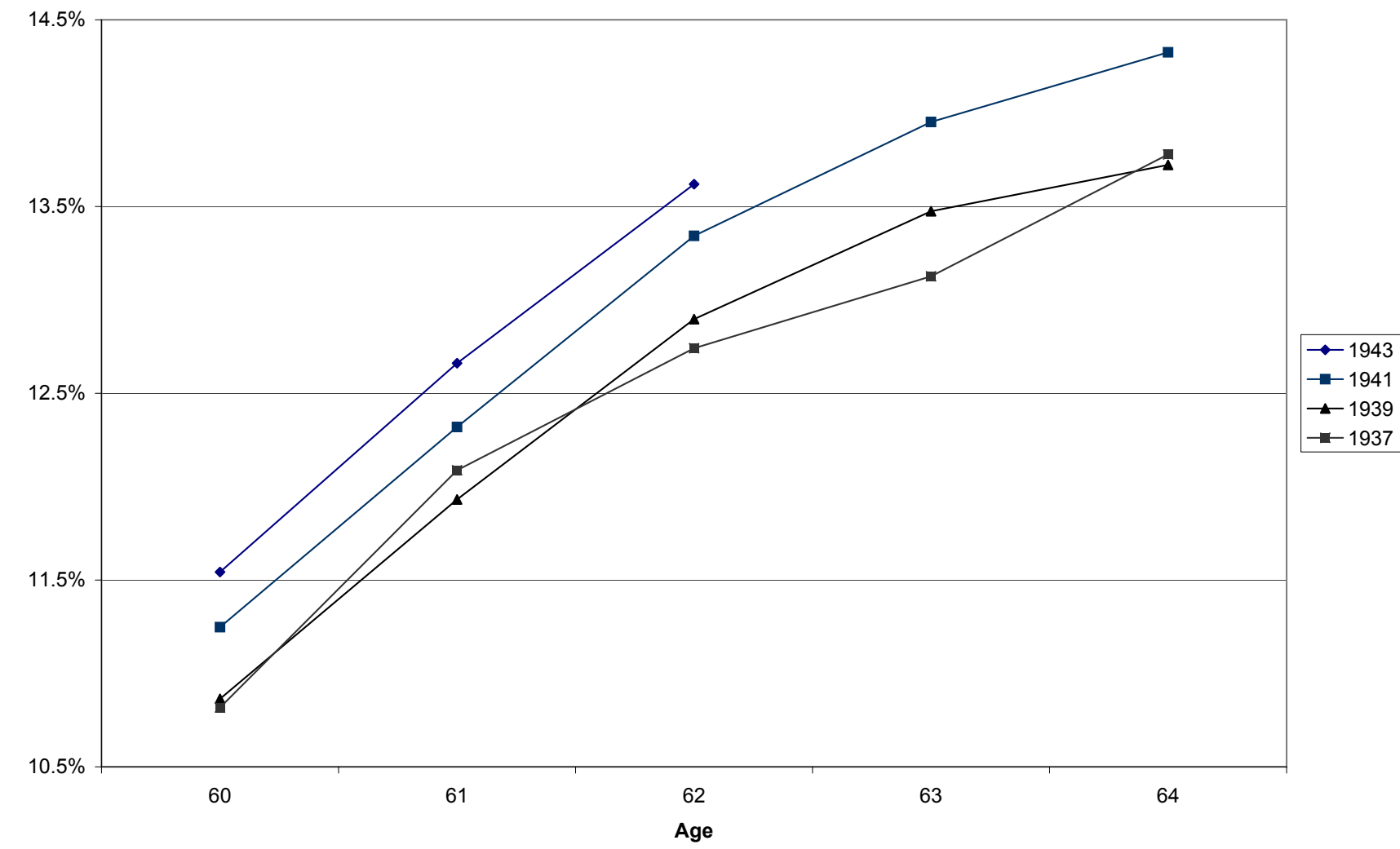

Figure 4B: Percent of Women Receiving SSDI by Age and Year-of-Birth

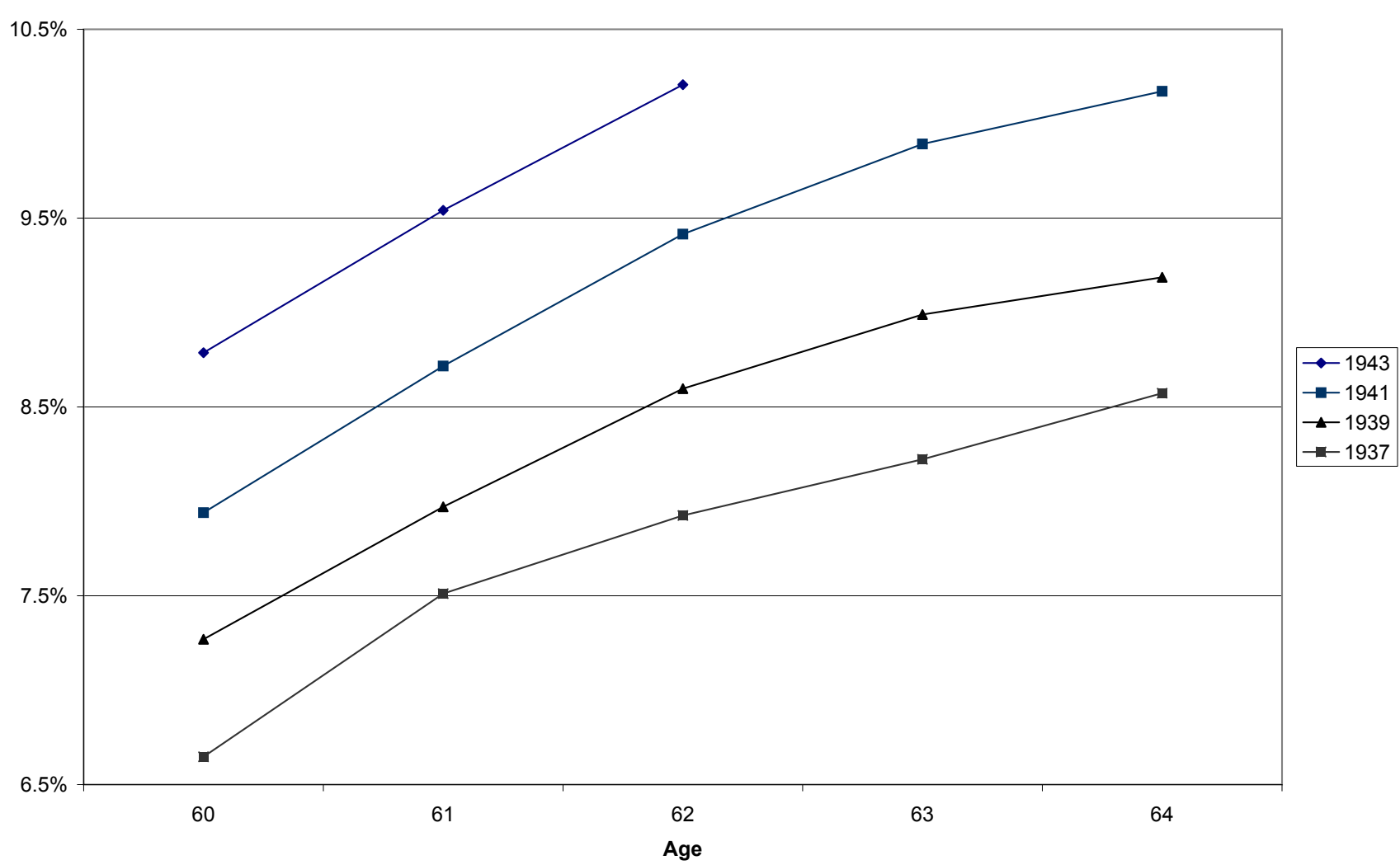


Figure 5A: Percent of Men Age 62 Receiving SSDI by Year-of-Birth

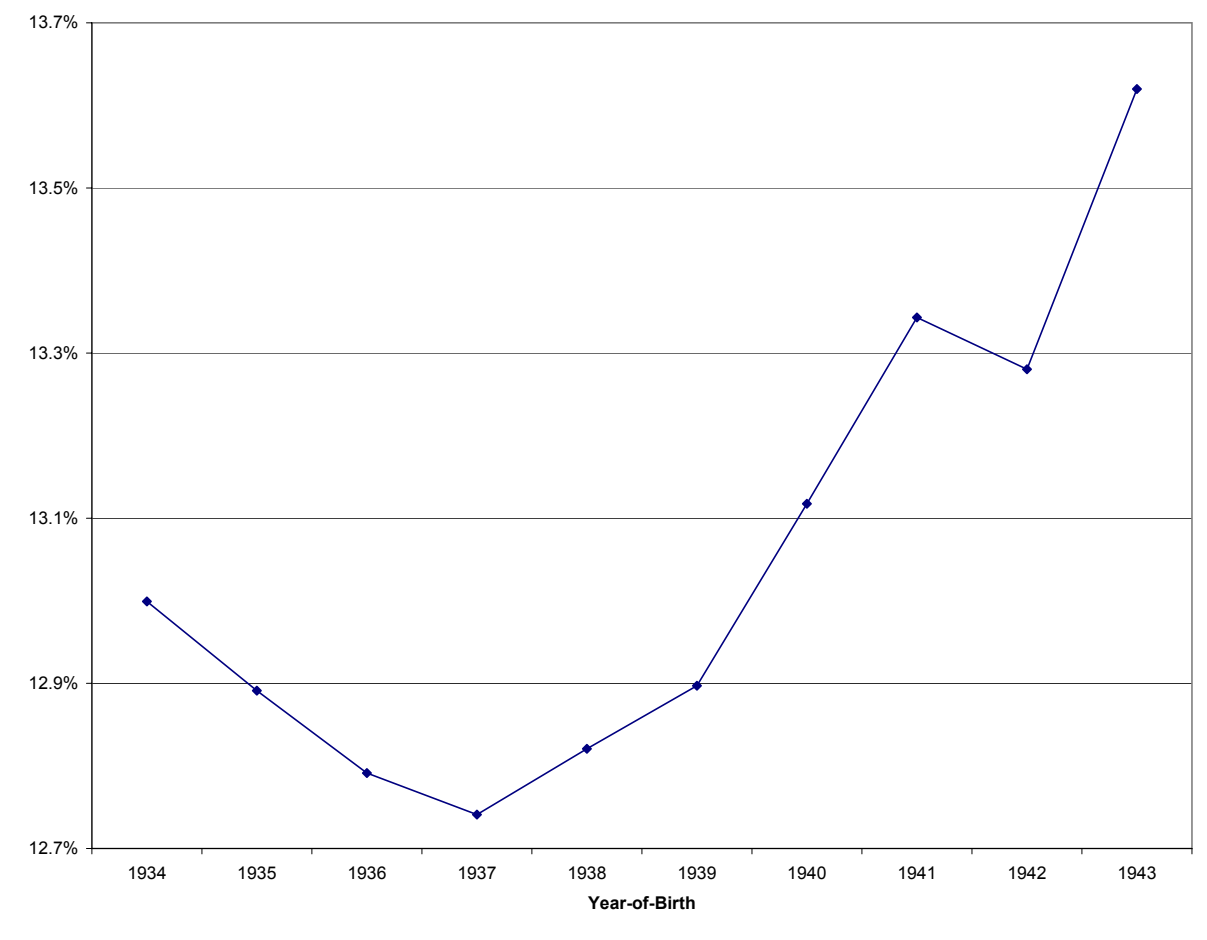

Figure 5C: Percent of Men Age 52 Receiving SSDI by Year-of-Birth

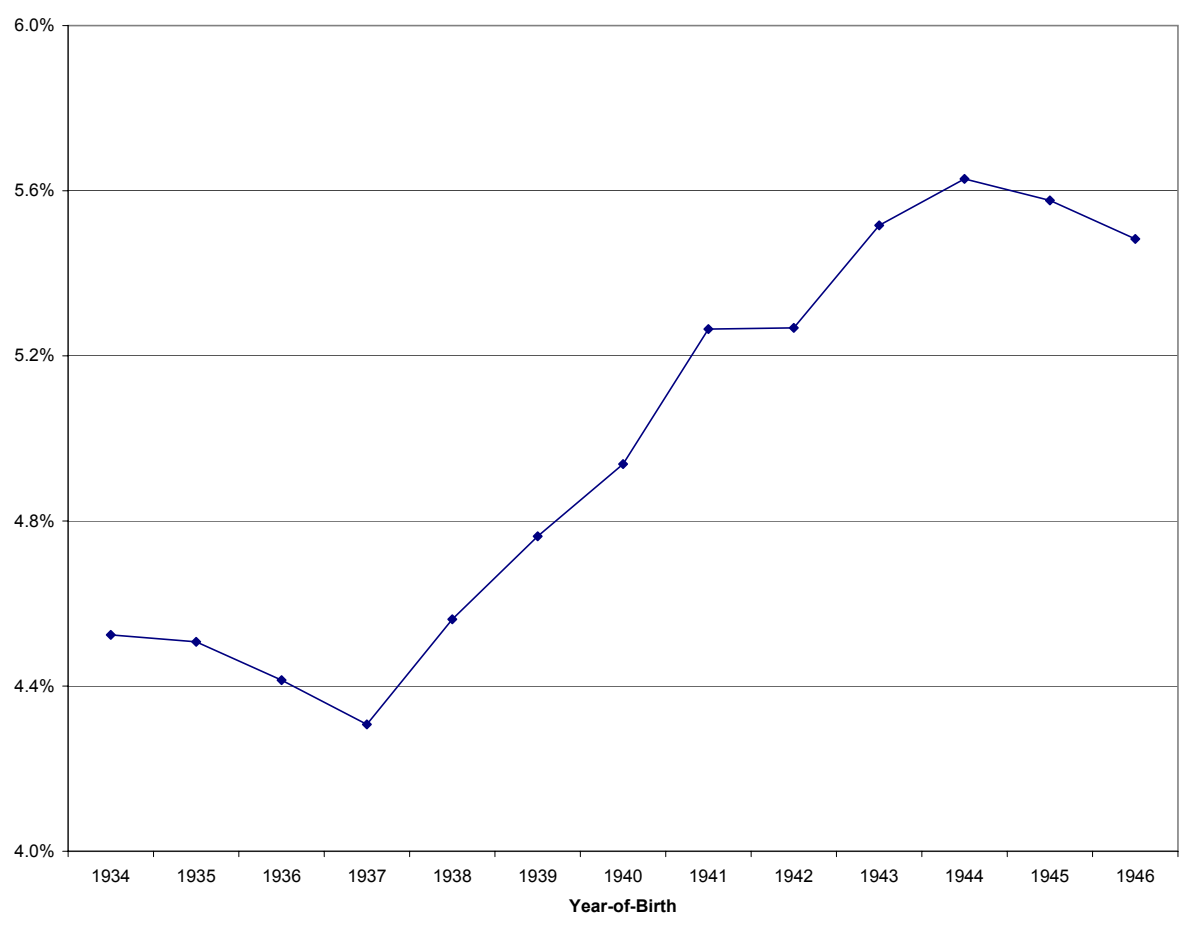

Figure 5B: Percent of Women Age 62 Receiving SSDI by Year-of-Birth

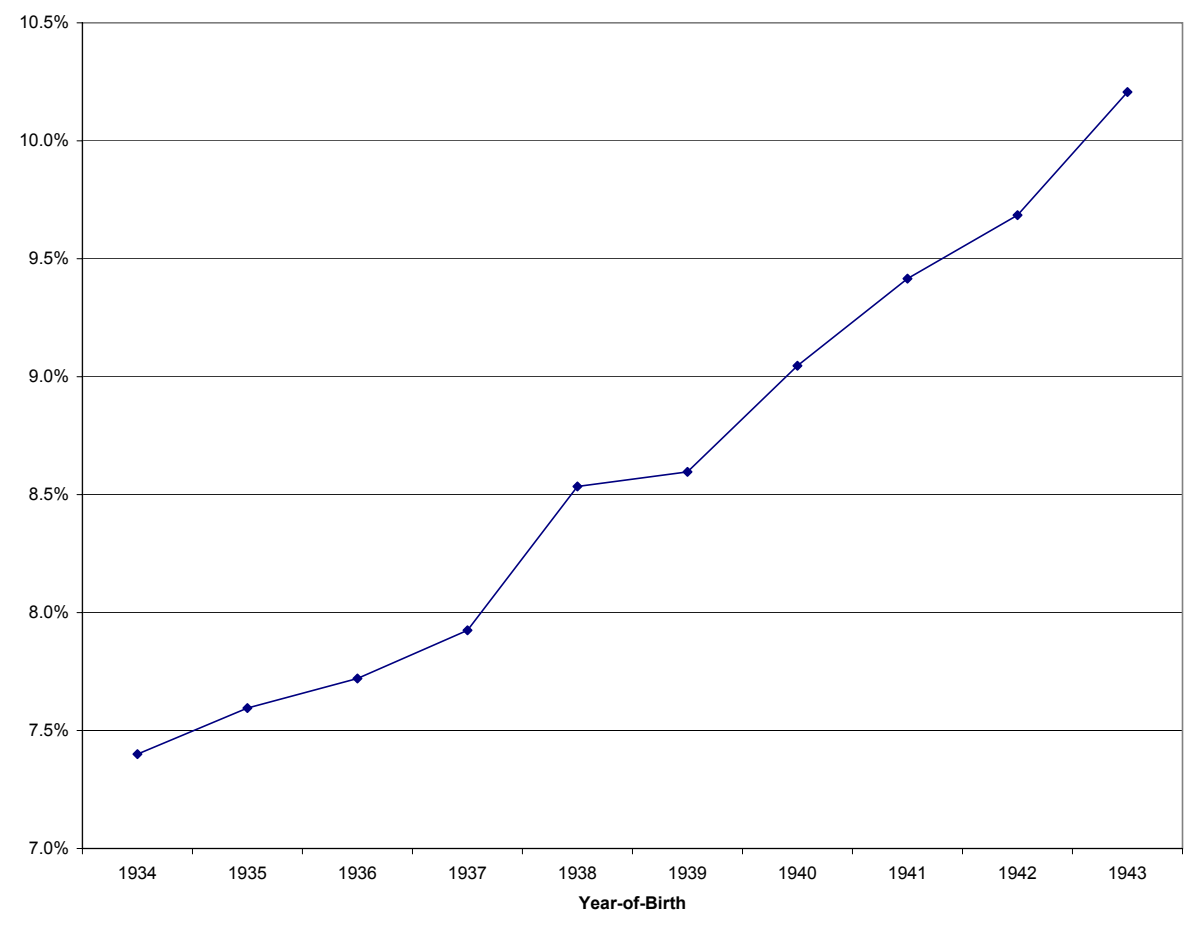

Figure 5D: Percent of Women Age 52 Receiving SSDI by Year-of-Birth

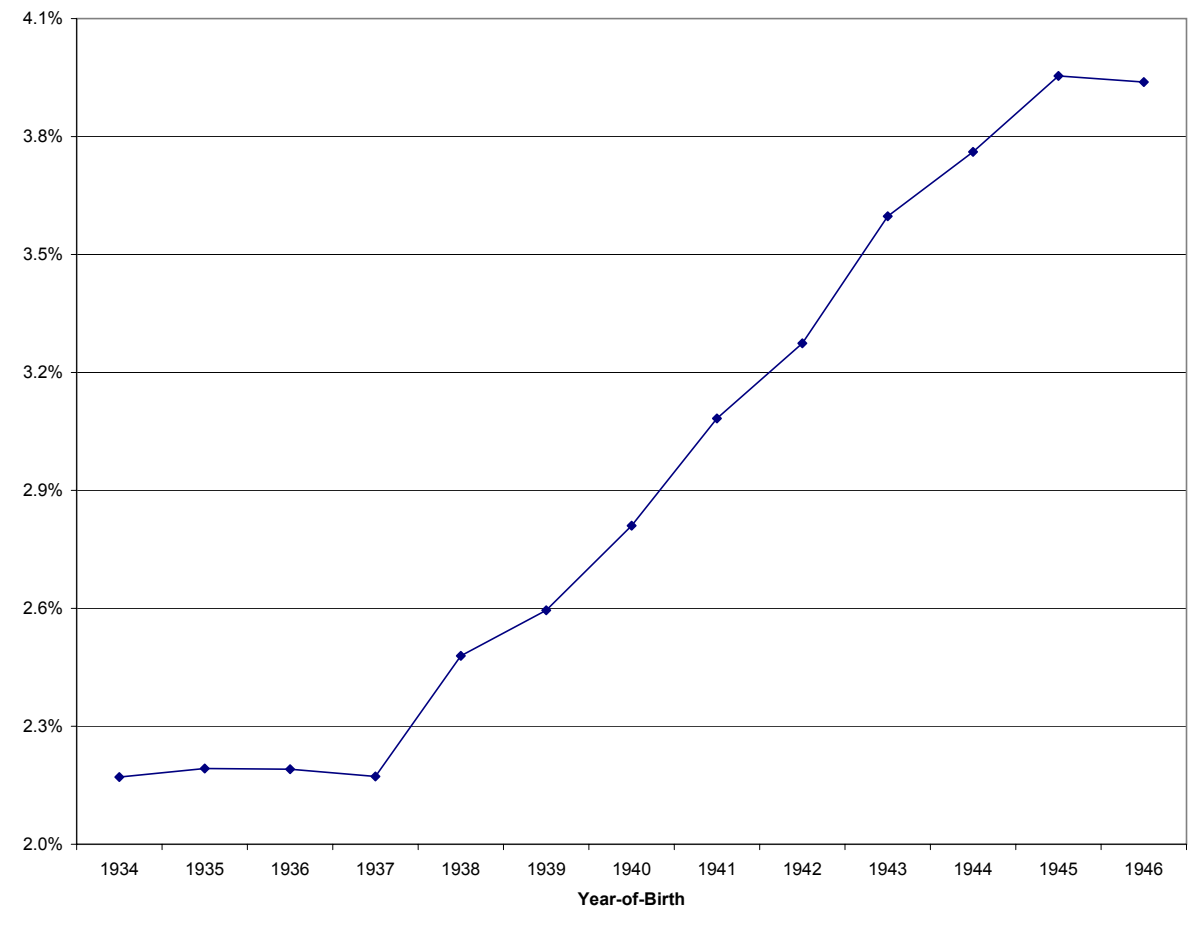


Table 1: Average Present Value of Social Security Retired Worker Benefits by Gender and Birth Cohort

Men by Year-of-Birth

Women by Year-of-Birth

$\begin{array}{ccccccccc}\text { age } & <=1937 & 1943-1954 & >=1960 & \text { ANNUAL } \Delta & <=1937 & 1943-1954 & >=1960 & \text { ANNUAL } \Delta \\ 45 & \$ 75,452 & \$ 70,736 & \$ 66,020 & -\$ 786 & \$ 56,829 & \$ 53,277 & \$ 49,726 & -\$ 592 \\ 46 & \$ 78,019 & \$ 73,143 & \$ 68,267 & -\$ 813 & \$ 58,667 & \$ 55,000 & \$ 51,334 & -\$ 611 \\ 47 & \$ 80,700 & \$ 75,656 & \$ 70,612 & -\$ 841 & \$ 60,575 & \$ 56,789 & \$ 53,003 & -\$ 631 \\ 48 & \$ 83,501 & \$ 78,282 & \$ 73,063 & -\$ 870 & \$ 62,557 & \$ 58,647 & \$ 54,737 & -\$ 652 \\ 49 & \$ 86,429 & \$ 81,027 & \$ 75,626 & -\$ 900 & \$ 64,616 & \$ 60,577 & \$ 56,539 & -\$ 673 \\ 50 & \$ 89,492 & \$ 83,899 & \$ 78,305 & -\$ 932 & \$ 66,755 & \$ 62,583 & \$ 58,411 & -\$ 695 \\ 51 & \$ 92,700 & \$ 86,906 & \$ 81,112 & -\$ 966 & \$ 68,980 & \$ 64,669 & \$ 60,358 & -\$ 719 \\ 52 & \$ 96,065 & \$ 90,061 & \$ 84,057 & -\$ 1,001 & \$ 71,297 & \$ 66,841 & \$ 62,385 & -\$ 743 \\ 53 & \$ 99,598 & \$ 93,373 & \$ 87,148 & -\$ 1,037 & \$ 73,714 & \$ 69,107 & \$ 64,500 & -\$ 768 \\ 54 & \$ 103,311 & \$ 96,854 & \$ 90,397 & -\$ 1,076 & \$ 76,237 & \$ 71,472 & \$ 66,707 & -\$ 794 \\ 55 & \$ 107,218 & \$ 100,517 & \$ 93,816 & -\$ 1,117 & \$ 78,876 & \$ 73,947 & \$ 69,017 & -\$ 822 \\ 56 & \$ 111,337 & \$ 104,378 & \$ 97,420 & -\$ 1,160 & \$ 81,641 & \$ 76,539 & \$ 71,436 & -\$ 850 \\ 57 & \$ 115,690 & \$ 108,459 & \$ 101,229 & -\$ 1,205 & \$ 84,543 & \$ 79,259 & \$ 73,975 & -\$ 881 \\ 58 & \$ 120,304 & \$ 112,785 & \$ 105,266 & -\$ 1,253 & \$ 87,592 & \$ 82,118 & \$ 76,643 & -\$ 912 \\ 59 & \$ 125,209 & \$ 117,384 & \$ 109,558 & -\$ 1,304 & \$ 90,803 & \$ 85,128 & \$ 79,453 & -\$ 946 \\ 60 & \$ 130,442 & \$ 122,290 & \$ 114,137 & -\$ 1,359 & \$ 94,191 & \$ 88,304 & \$ 82,417 & -\$ 981 \\ 61 & \$ 136,043 & \$ 127,540 & \$ 119,038 & -\$ 1,417 & \$ 97,772 & \$ 91,662 & \$ 85,551 & -\$ 1,018 \\ 62 & \$ 142,055 & \$ 133,176 & \$ 124,298 & -\$ 1,480 & \$ 101,569 & \$ 95,221 & \$ 88,873 & -\$ 1,058 \\ 63 & \$ 137,871 & \$ 129,254 & \$ 120,637 & -\$ 1,436 & \$ 98,872 & \$ 92,693 & \$ 86,513 & -\$ 1,030 \\ 64 & \$ 133,675 & \$ 125,320 & \$ 116,966 & -\$ 1,392 & \$ 96,154 & \$ 90,144 & \$ 84,135 & -\$ 1,002\end{array}$

Values displayed in this table represent the average present value of retired worker benefits for three different groups - those unaffected by the 1983 Amendments (born in or before 1937), those affected by half of the long-run reduction in benefit generosity (born between 1943 and 1954), and those fully affected by the reduction in benefit generosity (born in or after 1960). For these present value calculations, we use equations (1) and (2) from the text. We use the average PIA for retired worker beenfits in 1999 for men (\$1061) and for women (\$674), a 3 percent annual discount rate, and the age and gender specific mortality rates from the SSA's Office of the Actuary. The Annual $\Delta$ column represents the annual average change in this present value during the phase-in periods from cohort 1937 to 1943 and from cohort 1954 to 1960. 
Table 2: Cohort and Age Group Considered in Each Year: 1984-2005

\begin{tabular}{|c|c|c|c|c|c|c|c|c|c|c|c|c|c|c|c|c|c|c|c|c|c|c|}
\hline Year & Cohorts & 45 & 46 & 47 & 48 & 49 & 50 & 51 & 52 & 53 & 54 & 55 & 56 & 57 & 58 & 59 & 60 & 61 & 62 & 63 & 64 & Tota \\
\hline 1984 & 1934-1944 & $\mathrm{T}$ & $\mathrm{T}$ & C & C & C & & & & & & & & & & & & & & & & 5 \\
\hline 1985 & 1934-1945 & $\mathrm{T}$ & $\mathrm{T}$ & $\mathrm{T}$ & C & C & C & & & & & & & & & & & & & & & 6 \\
\hline 1986 & 1934-1946 & $\mathrm{T}$ & $\mathrm{T}$ & $\mathrm{T}$ & $\mathrm{T}$ & C & C & C & & & & & & & & & & & & & & 7 \\
\hline 1988 & 1934-1946 & $\mathrm{T}$ & $\mathrm{T}$ & $\mathrm{T}$ & $\mathrm{T}$ & $\mathrm{T}$ & $\mathrm{T}$ & C & C & C & & & & & & & & & & & & 9 \\
\hline 1989 & 1934-1946 & C & $\mathrm{T}$ & $T$ & $\mathrm{~T}$ & $\mathrm{~T}$ & $T$ & $\mathrm{~T}$ & C & C & C & & & & & & & & & & & 10 \\
\hline 1990 & 1934-1946 & C & C & $T$ & $\mathrm{~T}$ & $\mathrm{~T}$ & $T$ & $\mathrm{~T}$ & $\mathrm{~T}$ & C & C & C & & & & & & & & & & 11 \\
\hline 1993 & $1934-1946$ & & & $C$ & C & C & $\mathrm{T}$ & $\mathrm{T}$ & $\mathrm{T}$ & $T$ & $\mathrm{~T}$ & $T$ & $C$ & $\mathrm{C}$ & C & & & & & & & 12 \\
\hline 1994 & $1934-1946$ & & & & C & C & $C$ & $\mathrm{~T}$ & $\mathrm{~T}$ & $T$ & $\mathrm{~T}$ & $T$ & $\mathrm{~T}$ & $\mathrm{C}$ & C & $\mathrm{C}$ & & & & & & 12 \\
\hline 1995 & $1934-1946$ & & & & & C & $C$ & $C$ & $\mathrm{~T}$ & $T$ & $\mathrm{~T}$ & $\mathrm{~T}$ & $T$ & $\mathrm{~T}$ & C & $\mathrm{C}$ & $C$ & & & & & 12 \\
\hline 1996 & $1934-1946$ & & & & & & $C$ & $C$ & C & $T$ & $T$ & $\mathrm{~T}$ & $T$ & $T$ & $\mathrm{~T}$ & C & $C$ & $\mathrm{C}$ & & & & 12 \\
\hline 1997 & $1934-1946$ & & & & & & & $C$ & $C$ & $\mathrm{C}$ & $\mathrm{T}$ & $\mathrm{T}$ & $T$ & $\mathrm{~T}$ & $\mathrm{~T}$ & $\mathrm{~T}$ & $C$ & $\mathrm{C}$ & C & & & 12 \\
\hline 1998 & $1934-1946$ & & & & & & & & C & $C$ & $C$ & $\mathrm{~T}$ & $T$ & $T$ & $\mathrm{~T}$ & $\mathrm{~T}$ & $\mathrm{~T}$ & $\mathrm{C}$ & $\mathrm{C}$ & $\mathrm{C}$ & & 12 \\
\hline 1999 & $1934-1946$ & & & & & & & & & $C$ & $C$ & C & $\mathrm{T}$ & $\mathrm{T}$ & $\mathrm{T}$ & $\mathrm{T}$ & $T$ & $\mathrm{~T}$ & C & $\mathrm{C}$ & $\mathrm{C}$ & 12 \\
\hline 2004 & $1939-1946$ & & & & & & & & & & & & & & C & C & $C$ & $\mathrm{~T}$ & $\mathrm{~T}$ & $\mathrm{~T}$ & $\mathrm{~T}$ & 7 \\
\hline 2005 & $1940-1946$ & & & & & & & & & & & & & & & C & C & C & $\mathrm{T}$ & $\mathrm{T}$ & $\mathrm{T}$ & 6 \\
\hline Total & 215 & 8 & 9 & 10 & 11 & 12 & 12 & 12 & 12 & 12 & 12 & 12 & 12 & 12 & 12 & 12 & 11 & 10 & 9 & 8 & 7 & 215 \\
\hline
\end{tabular}

Each row of the table lists the treatment $(T)$ and control $(C)$ groups in a particular year and at each age for the specifications summarized in Table 3 and in the first three specifications of Table 4, which utilize SSDI enrollment data for the $1934-1946$ birth cohorts. The variable $\triangle P V R$ is equal to 0 if an age-year cell is denoted $\mathrm{C}$ and is otherwise equal to the value listed in Table 1 for each specific age. Thus $\Delta \mathrm{PVR}$ is equal to 0 for 52 -year old men in the three first differences from 1987-1989 (which represent the changes from the 1934-35, 1935-36, and 1936-37 birth cohorts), is equal to -1.001 in the next six years (first differences from 1937-43), and is equal to 0 in the three first differences from 1996-1998 (first differences from 1943-46). 
Table 3: The Impact of Changes in Retired Worker Benefits on Male and Female SSDI Enrollment

Men

Women

$\begin{array}{lllllll}1 & (2) & (3) & (4) & (5) & (6) & \text { (4) }\end{array}$

$\begin{array}{lcccccccc}\Delta \text { PVR } & -.0778^{* *} & -.1066^{* *} & -.0736^{* *} & -.0918^{*} & -.1639^{* *} & -.1302^{\star *} & -.1915^{\star *} & -.1242^{* *} \\ & (.0334) & (.0489) & (.0307) & (.0499) & (.0642) & (.0464) & (.0840) & (.0463)\end{array}$

$\Delta \mathrm{PVR} *$ (Age 55-64)

0.0217

$-0.0630$

$(.0378)$

(.0651)

$\begin{array}{ccccccccc}\text { Ages Included } & 45-64 & 45-54 & 55-64 & 45-64 & 45-64 & 45-54 & 55-64 & 45-64 \\ \text { Years Included } & 1984-2005 & 1984-2000 & 1990-2005 & 1984-2005 & 1984-2005 & 1984-2000 & 1990-2005 & 1984-2005 \\ \text { \# Observations } & 215 & 110 & 105 & 215 & 215 & 110 & 105 & 215 \\ \text { Mean of } \Delta \text { SSDI } & 0.0858 & 0.0923 & 0.0789 & 0.0858 & 0.1910 & 0.1266 & 0.2584 & 0.1910 \\ \text { Mean of } \Delta \text { OA PV } & -0.600 & -0.496 & -0.710 & -0.600 & -0.440 & -0.370 & -0.514 & -0.440 \\ \text { R-squared } & 0.505 & 0.555 & 0.502 & 0.506 & 0.536 & 0.627 & 0.375 & 0.573\end{array}$

The dependent variable is equal to the fraction of men (specifications 1-4) or women (specifications 5-8) on SSDI in an age-year cell. The unit of observation is age*year. The ages included in each year are listed in Table 2. The variable $\triangle P V R$ is equal to the change in the present value of retired worker benefits in an age cell from one year to the next. All first difference regressions include 22 year effects and 20 age effects. Standard errors are included in parentheses and are clustered by year-of-birth. $\triangle$ SSDI is measured in percentage points and $\triangle$ PVR is measured in thousands of 1999 dollars.

Table 4: The Impact of Changes in Retired Worker Benefits on Overall SSDI Enrollment

$\begin{array}{ccccccccc} & (1) & (2) & (3) & (4) & (5) & (6) & (7) & (8) \\ \Delta \mathrm{PVR} & -.1151^{* *} & -.1168^{* *} & -.1240^{* *} & -.0834 & -.0866^{* *} & -.0731^{* *} & -.1129^{* *} & -.0803^{*} \\ & (.0404) & (.0455) & (.0440) & (.0668) & (.0351) & (.0365) & (.0423) & (.0414) \\ \text { Ages Included } & 45-64 & 45-54 & 55-64 & 45-56 & 45-64 & 45-54 & 55-64 & 45-64 \\ \text { Years Included } & 1984-2005 & 1984-2000 & 1990-2005 & 1994-2005 & 1984-2005 & 1984-2005 & 1990-2005 & 1984-2005 \\ \text { Cohorts Included } & 1934-46 & 1934-46 & 1934-46 & 1948-60 & 1934-60 & 1934-60 & 1934-50 & 1920-60 \\ \text { \# Observations } & 215 & 110 & 105 & 78 & 320 & 220 & 115 & 440 \\ \text { Mean of } \Delta \text { SSDI } & 0.1415 & 0.1105 & 0.1740 & 0.0961 & 0.1323 & 0.1085 & 0.1747 & 0.1198 \\ \text { Mean of } \Delta \text { OA PV } & -0.520 & -0.433 & -0.612 & -0.196 & -0.397 & -0.307 & -0.559 & -0.289 \\ \text { R-squared } & 0.533 & 0.607 & 0.454 & 0.258 & 0.431 & 0.371 & 0.412 & 0.358\end{array}$

The dependent variable is equal to the fraction of individuals on SSDI in an age-year cell. The unit of observation is age*year. The ages included in each year are listed in Table 2 . The variable $\Delta \mathrm{PVR}$ is equal to the change in the present value of retired worker benefits in an age cell from one year to the next. All first difference regressions include 22 year effects and 20 age effects. Standard errors are included in parentheses and are clustered by year-of-birth. $\triangle$ SSDI is measured in percentage points and $\triangle \mathrm{PVR}$ is measured in thousands of 1999 dollars. 
Table 5: Implied Effect of Change in Present Value of Retired Worker Benefits on SSDI Enrollment

Dec-05

$\begin{array}{cccccc}\text { Age } & \text { YOB } & \text { PV } \Delta & \text { FRA Impact } & \text { Actual } \Delta & \text { Long-Run } \\ 45 & 1960 & \$ 9,432 & 0.73 \% & 1.55 \% & 0.73 \% \\ 46 & 1959 & \$ 8,940 & 0.70 \% & 1.69 \% & 0.76 \% \\ 47 & 1958 & \$ 8,406 & 0.65 \% & 1.82 \% & 0.79 \% \\ 48 & 1957 & \$ 7,828 & 0.61 \% & 1.68 \% & 0.81 \% \\ 49 & 1956 & \$ 7,202 & 0.56 \% & 1.87 \% & 0.84 \% \\ 50 & 1955 & \$ 6,525 & 0.51 \% & 1.84 \% & 0.87 \% \\ 51 & 1954 & \$ 5,794 & 0.45 \% & 1.58 \% & 0.90 \% \\ 52 & 1953 & \$ 6,004 & 0.47 \% & 1.73 \% & 0.93 \% \\ 53 & 1952 & \$ 6,225 & 0.48 \% & 1.87 \% & 0.97 \% \\ 54 & 1951 & \$ 6,457 & 0.50 \% & 2.25 \% & 1.01 \% \\ 55 & 1950 & \$ 6,701 & 0.52 \% & 1.77 \% & 1.04 \% \\ 56 & 1949 & \$ 6,959 & 0.54 \% & 1.87 \% & 1.08 \% \\ 57 & 1948 & \$ 7,231 & 0.56 \% & 2.01 \% & 1.13 \% \\ 58 & 1947 & \$ 7,519 & 0.59 \% & 1.54 \% & 1.17 \% \\ 59 & 1946 & \$ 7,826 & 0.61 \% & 1.54 \% & 1.22 \% \\ 60 & 1945 & \$ 8,153 & 0.63 \% & 1.47 \% & 1.27 \% \\ 61 & 1944 & \$ 8,503 & 0.66 \% & 1.29 \% & 1.32 \% \\ 62 & 1943 & \$ 8,878 & 0.69 \% & 0.90 \% & 1.38 \% \\ 63 & 1942 & \$ 7,181 & 0.56 \% & 0.84 \% & 1.34 \% \\ 64 & 1941 & \$ 5,570 & 0.43 \% & 0.56 \% & 1.30 \% \\ \text { All 45-64 } & 1941-60 & \$ 7,391 & 0.58 \% & 1.64 \% & 1.00 \%\end{array}$

Women

$\begin{array}{cccc}\text { PV } \Delta & \text { FRA Impact } & \text { Actual } \Delta & \text { Long-Run } \\ \$ 7,104 & 1.16 \% & 2.21 \% & 1.16 \% \\ \$ 6,722 & 1.10 \% & 2.42 \% & 1.20 \% \\ \$ 6,310 & 1.03 \% & 2.53 \% & 1.24 \% \\ \$ 5,865 & 0.96 \% & 2.60 \% & 1.28 \% \\ \$ 5,385 & 0.88 \% & 2.81 \% & 1.32 \% \\ \$ 4,868 & 0.80 \% & 2.93 \% & 1.37 \% \\ \$ 4,311 & 0.71 \% & 3.04 \% & 1.41 \% \\ \$ 4,456 & 0.73 \% & 3.20 \% & 1.46 \% \\ \$ 4,607 & 0.76 \% & 3.45 \% & 1.51 \% \\ \$ 4,765 & 0.78 \% & 3.63 \% & 1.56 \% \\ \$ 4,930 & 0.81 \% & 3.54 \% & 1.62 \% \\ \$ 5,103 & 0.84 \% & 3.78 \% & 1.67 \% \\ \$ 5,284 & 0.87 \% & 4.14 \% & 1.73 \% \\ \$ 5,475 & 0.90 \% & 3.99 \% & 1.79 \% \\ \$ 5,675 & 0.93 \% & 4.26 \% & 1.86 \% \\ \$ 5,887 & 0.96 \% & 4.44 \% & 1.93 \% \\ \$ 6,111 & 1.00 \% & 4.60 \% & 2.00 \% \\ \$ 6,348 & 1.04 \% & 4.61 \% & 2.08 \% \\ \$ 5,150 & 0.84 \% & 4.35 \% & 2.03 \% \\ \$ 4,006 & 0.66 \% & 4.23 \% & 1.97 \% \\ \$ 5,448 & 0.89 \% & 3.41 \% & 1.56 \%\end{array}$

Table summarizes the estimated effect of changes in Social Security retired worker benefits on the fraction of individuals receiving SSDI benefits by December of 2005. PV $\Delta$ columns lists the average change in the present value of retired worker benefits by age for men and women in 2005. The FRA Impact columns represent the estimated effect of this change on the fraction receiving SSDI, using the parameter estimates for men and women from specifications (1) and (5), respectively, in Table 3. Actual $\Delta$ columns list the actual change in age-specific SSDI enrollment, and Long-Run columns list out estimates of the effect once the policy change is fully phased in (i.e. individuals born in 1960 or later at each age). 